BERRÍOS, Gonzalo. “La ley de responsabilidad penal del adolescente como sistema de justicia: análisis y propuestas".

Polít. crim. Vol. 6, № 11 (Junio 2011), Art. 6, pp. 163-191.

[http://www.politicacriminal.cl/Vol_06/n_11/Vol6N11A6.pdf]

\title{
La ley de responsabilidad penal del adolescente como sistema de justicia: análisis y propuestas*
}

\author{
Gonzalo Berríos Díaz \\ Magíster en Derecho Penal y Procesal Penal, Profesor invitado Facultad de Derecho \\ Universidad de Chile y Facultad de Ciencias Jurídicas Universidad Central \\ Berrios.gonzalo@gmail.com
}

\section{Resumen}

El presente artículo analiza la aplicación de la Ley de Responsabilidad Penal del Adolescente en relación con los objetivos que ésta debe alcanzar en el marco de la Convención sobre los Derechos del Niño. El trabajo identifica y define dichos objetivos, por ejemplo, la diferenciación de la justicia juvenil frente a la de adultos, el privilegio de la desjudicialización y el carácter excepcional de la privación de libertad, los que posteriormente son contrastados con la información producida a su respecto. Para ello, el trabajo realiza una amplia revisión y sistematización de diversos informes, estudios y estadísticas -los que también determinan sus limitaciones-, entregando una mirada global acerca del funcionamiento real del sistema de justicia penal para adolescentes. El artículo identifica importantes problemas no sólo en la aplicación, sino en el propio diseño legal de la justicia juvenil, que dificultan el logro de sus fines, para lo cual se propone impulsar reformas coherentes con la consecución de tales objetivos.

\section{Palabras claves}

Responsabilidad Penal Adolescente, Derechos del Niño, Sistema de Justicia Juvenil

\begin{abstract}
The article analyzes the application of Juvenile's Criminal Liability Act in terms of the objectives it must achieve in the context of the Convention on the Rights of the Child. The paper identifies and defines said objectives; for example, differentiating juvenile justice from adult justice, the privilege of diversion, and the exceptional nature of deprivation of liberty, which are later contrasted with the information gathered by the paper regarding these topics. Toward this end, the work undertakes a wide-ranging review and systemization of a number of reports, studies and statistics -which also determine its limitations - thereby providing an overall view of the real working of the juvenile criminal justice system. The article identifies important problems in both the application and the very design of juvenile justice that make the attainment of its goals difficult; hence, it proposes promoting coherent reforms that better achieve these goals.
\end{abstract}

\section{Key words}

Juvenile's Criminal Liability, Child's Rights, Juvenile Justice System 
BERRÍOS, Gonzalo. "La ley de responsabilidad penal del adolescente como sistema de justicia: análisis y propuestas".

\section{Introducción}

Este artículo se ocupa de describir y analizar el funcionamiento de la Ley 20.084 de Responsabilidad Penal del Adolescente (en adelante, LRPA) vigente en Chile desde el 8 de junio de 2007. La Ley es parte fundamental de un derecho penal especial -juvenil o de adolescentes- que se caracteriza porque a los jóvenes, además de las garantías penales y procesales comunes a todas las personas, se les han de reconocer mayores derechos y garantías. El fundamento de esta protección especial radica en la aplicación de los principios de igualdad y de protección, pues la diferente situación jurídico-social del adolescente y su calidad de persona en pleno proceso de desarrollo, lo hacen merecedor de una mayor protección jurídica de sus derechos. ${ }^{1}$ La LRPA comprende a los adolescentes de 14 a 17 años que hayan cometido alguno de los delitos establecidos por la ley penal general, salvo ciertas excepciones, en un marco de pleno reconocimiento de los derechos y garantías que integran el debido proceso. En caso de declararse judicialmente la responsabilidad penal, se les aplican sanciones privativas o no privativas de libertad especialmente previstas para los jóvenes, las que siempre podrán revisarse y modificarse durante su fase de ejecución.

El análisis apunta a valorar si en los tres primeros años de funcionamiento de la Ley se ha dado cumplimiento a los objetivos que la legislación debiera alcanzar. Si bien el diseño legal puede resultar clave para explicar ciertos comportamientos, el presente estudio no realiza un análisis normativo de la Ley, sino más bien un análisis del sistema de justicia juvenil que se ha configurado en torno a las normas, instituciones y objetivos de la Ley. Este enfoque se basa en la idea de que "la justicia criminal como un todo es la resultante de la interacción entre las reglas legales, las prácticas administrativas y las actitudes y comportamientos sociales". ${ }^{2}$ Se trata, en definitiva, de analizar cómo se ha configurado el sistema de justicia juvenil a partir de su funcionamiento práctico.

Para alcanzar el propósito anterior se realizará, en primer lugar, una identificación de los principales objetivos que debiera perseguir la justicia penal para adolescentes, para lo cual se recurrirá al examen de los fines del legislador, a los principios de la Convención sobre los Derechos del Niño (en adelante, CDN) y a las elaboraciones efectuadas por la doctrina nacional.

En segundo lugar, como estos objetivos debieran reflejarse en las prácticas del sistema de justicia, su identificación servirá para establecer los puntos de referencia del análisis y valoración del funcionamiento de la LRPA. El principal recurso que se utilizará para

\footnotetext{
* Este artículo, salvo ajustes por razones editoriales, corresponde a la contribución del autor al Libro Homenaje que prepara el Departamento de Ciencias Penales de la Facultad de Derecho de la Universidad de Chile, en memoria de los destacados profesores de derecho penal de dicha casa de estudios fallecidos durante los últimos años.

${ }^{1}$ Véase BUSTOS RAMÍREZ, Juan, "Hacia la desmitificación de la facultad reformadora en el derecho penal de menores: por un derecho penal del menor", en: BUSTOS RAMÍREZ, Juan (Dir.), Un derecho penal del menor, Santiago: Ed. Jurídica Cono Sur, 1992, p. 7.

${ }^{2}$ HAZARD JR., Geoffrey, “Criminal justice system: overview”, Encyclopedia of Crime and Justice, Vol. 2, New York: The Free Press, 1988, pp. 450 y ss., citado por DUCE, Mauricio; RIEGO, Cristián, Proceso penal, Santiago: Ed. Jurídica de Chile, 2007, pp. 17 y 18.
} 
Polít. crim. Vol. 6, Nº 11 (Junio 2011), Art. 6, pp. 163-191.

[http://www.politicacriminal.cl/Vol_06/n_11/Vol6N11A6.pdf]

desarrollar esta tarea será la información estadística levantada por instituciones relacionadas con la justicia juvenil, lo que permitirá un acercamiento cuantitativo a la dinámica de operación del sistema de justicia generado en torno a la aplicación de la Ley.

Por último, junto con las conclusiones se realizarán algunas proposiciones de lege ferenda que pudieran optimizar el grado de satisfacción de las finalidades perseguidas por la ley penal juvenil chilena. Además, se realizarán otras propuestas vinculadas a los distintos hallazgos del estudio.

\section{El rol de la Convención sobre los Derechos del Niño en la determinación de los objetivos del nuevo sistema penal de adolescentes}

Aunque es frecuente que los objetivos de una determinada legislación no estén completa o expresamente declarados, ni aparezcan de manifiesto en la ley misma, sobre la base de sus antecedentes históricos, normativos, científico sociales y doctrinarios, aquellos fines pueden ser efectivamente reconstruidos y sistematizados. Por lo demás, una cuestión no muy distinta a la señalada es la función de ciertas clases de argumentaciones propias de la aplicación del Derecho, por lo que no debiera de resultar extraño recurrir a las mismas para establecer ya no el sentido de las normas, sino los objetivos del nuevo sistema penal juvenil establecido por la Ley 20.084.

La determinación de los propósitos perseguidos por la Ley es relevante en el marco del presente trabajo, pues permitirá contrastar tales objetivos con la información cuantitativa de que se dispone acerca del funcionamiento real del sistema penal de adolescentes. En todo caso, es necesario precisar que los objetivos que interesan a los fines de este artículo serán sólo aquellos relacionados con aspectos sistémicos y cuantificables del funcionamiento de la justicia juvenil, excluyéndose del análisis los problemas estrictamente jurídicos que presenta la Ley.

En el caso chileno el legislador expresamente declaró en la exposición de motivos del proyecto de ley que pretende realizar una:

"completa reformulación de las leyes y políticas relativas a la infancia y la adolescencia, de modo de adecuarlas (...) a los principios y directrices contenidos en la Constitución Política de la República, la Convención Internacional sobre los Derechos del Niño y demás instrumentos internacionales vigentes en Chile". 3

Este proceso de adecuación a la Convención sobre los Derechos del Niño, si bien no fue la única razón para modificar el sistema penal y tutelar de los menores de edad, ${ }^{4}$ sí fue el

\footnotetext{
3 "Mensaje de S.E. el Presidente de la República con el que inicia un proyecto de ley que establece un sistema de responsabilidad de los adolescentes por infracciones a la ley penal (boletín $\mathrm{N}^{\circ}$ 3021-07)", Boletín de Sesiones de la Cámara de Diputados, Sesión 24a , de 6 de agosto de 2002, Legislatura 347ª Ordinaria, p. 72.

${ }^{4}$ Sobre las "otras razones" véase BERRÍOS, Gonzalo, "El nuevo sistema de justicia penal para adolescentes", Revista de Estudios de la Justicia $\mathrm{N}^{\circ} 6$ (2005), p. 163. Por su parte, Cillero y Bernales destacan el "aumento significativo de la carga punitiva sobre los adolescentes" que se introdujo en el proyecto de ley producto de la presión de los discursos de "ley y orden”: CILLERO, Miguel; BERNALES, Martín, "Derechos humanos de la
} 
BERRÍOS, Gonzalo. "La ley de responsabilidad penal del adolescente como sistema de justicia: análisis y propuestas".

factor predominante, tanto en el proceso pre-legislativo, ${ }^{5}$ como en el proceso propiamente parlamentario de elaboración de la nueva legislación.

También es una razón fuerte para considerar como aspecto central de la génesis de la Ley 20.084 el proceso de ajuste de las leyes nacionales a la CDN, el carácter constitucional que presentan los derechos del niño en cuanto están asegurados en un tratado internacional de derechos humanos. ${ }^{6}$ Tal carácter significa para el Estado la obligación de modificar sustancialmente todas las leyes nacionales que sean incompatibles con las normas de la Convención, como era el caso de la Ley de Menores y del Código Penal con respecto al tratamiento jurídico de las infracciones penales cometidas por personas menores de dieciocho años de edad. ${ }^{7}$ Esta misma consideración sobre su jerarquía normativa implica, a su vez, el deber de tener presente la $\mathrm{CDN}$ a efectos de realizar una "interpretación conforme a la Constitución" - o más claramente, una "interpretación conforme a la Convención" - de la LRPA, ${ }^{8}$ lo cual también es predicable del establecimiento de sus objetivos.

Por su parte, la doctrina nacional igualmente ha recurrido a los principios de la Convención para el desarrollo de sus tesis jurídicas y, más ampliamente, para la construcción de sus tesis político-criminales sobre la justicia penal para adolescentes. De ahí que en los párrafos que siguen revisemos los principales planteamientos de los autores nacionales, con especial énfasis en aquellos puntos que están relacionados con los objetivos de este trabajo.

De acuerdo con Couso, la CDN en sus artículos 37 y 40 establece ciertas garantías especiales de los adolescentes como expresión de su derecho a una respuesta penal especial, distinta de los adultos, ante las infracciones penales que cometan. Estos derechos particulares serían: 1) a una respuesta cualitativamente diferente de la de los adultos; 2) a una respuesta cuantitativamente menos aflictiva; 3) a especiales garantías durante la ejecución de las sanciones; y, 4) a que se fije una edad por debajo de la cual no se impondrá ninguna sanción. ${ }^{9}$

infancia/adolescencia en la justicia 'penal de menores' de Chile: evaluación y perspectivas", Revista de Derechos del Niño $\mathrm{N}^{\circ} 1$ (2002), pp. 31-33 y 37.

${ }^{5}$ Una revisión de todo el proceso previo a la Ley $\mathrm{N}^{\circ} 20.084$, en particular, de la especial consideración que se tuvo respecto de cumplir con los mandatos de la Convención sobre los Derechos del Niño, puede encontrarse en DE FERARI, Luis Ignacio, "Quince años de espera...hacia la creación de un sistema de reemplazo: notas sobre la génesis y desarrollo de la ley sobre responsabilidad penal de adolescentes", Revista Justicia y Derechos del Niño $\mathrm{N}^{\circ} 8$ (2006), pp. 113-158.

${ }^{6}$ NOGUEIRA ALCALÁ, Humberto, Derechos fundamentales y garantías constitucionales, t. 1, $2^{\mathrm{a}}$ edición corregida, Santiago: Ed. Librotecnia, 2008, en especial su cap. I, pp. 13-80.

${ }^{7}$ El propio "Mensaje", cit. nota $n^{\circ} 3$, p. 72 , señala que "esta reforma se fundamenta en que la actual legislación de menores, en no pocas materias, entra en contradicción con disposiciones de la Constitución y de la Convención Internacional sobre los Derechos del Niño y, en algunos casos, directamente vulneran estos cuerpos jurídicos" (las cursivas son nuestras).

${ }^{8}$ Método que, por ejemplo, propone Hernández para realizar también en el marco del derecho penal juvenil "la diferenciación no abordada explícitamente por la ley" en la teoría del delito. Véase HERNÁNDEZ BASUALTO, Héctor, "El nuevo derecho penal de adolescentes y la necesaria revisión de su "teoría del delito"”, en: VV. AA., Estudios de derecho penal juvenil I, Santiago: Centro de Documentación, Defensoría Penal Pública, 2009, p. 89.

${ }^{9}$ COUSO, Jaime, "La política criminal para adolescentes y la Ley 20.084", en: VV. AA., Estudios de derecho penal juvenil I, Santiago: Centro de Documentación, Defensoría Penal Pública, 2009, pp. 54 y 55. 
Polít. crim. Vol. 6, No 11 (Junio 2011), Art. 6, pp. 163-191.

[http://www.politicacriminal.cl/Vol_06/n_11/Vol6N11A6.pdf]

Como expresión de los derechos a una respuesta cualitativa y cuantitativamente diferente, el sistema penal juvenil debiera funcionar sobre la base de poder distinguir aquellos casos en que sea más conveniente emplear una estrategia despenalizadora y aquellos en los que se requeriría algún tipo de intervención penal mayor. Al primer grupo de casos se asocian diseños legales y operativos que permiten la aplicación de alternativas al proceso y a la sanción penal, en el caso chileno, mecanismos como el principio de oportunidad, los acuerdos reparatorios y la suspensión condicional del procedimiento. En cambio, por tratarse de las situaciones más graves, para el segundo grupo de casos se justificaría el empleo de las intervenciones penales propiamente tales, preferentemente por medio de la imposición de sanciones no privativas de libertad, y sólo excepcionalmente a través de la privación de libertad de los adolescentes. ${ }^{10}$

Para orientar la toma de decisiones en la aplicación de cada uno de los mecanismos procesales y penales mencionados, este autor identifica las principales necesidades políticocriminales sobre la base de dos grupos de supuestos: criminalidad leve o de mediana gravedad versus criminalidad grave, y criminalidad ocasional versus criminalidad habitual. $^{11}$

Desde otra perspectiva, de un exhaustivo análisis del derecho internacional de los derechos humanos se ha concluido por otro autor que respecto de los jóvenes se debe reconocer el derecho a un juzgamiento especializado de sus infracciones penales. En materia procesal penal, este derecho se puede descomponer en tres ejes centrales donde la especialidad se ha de manifestar con particular intensidad: 1) el reforzamiento del debido proceso; 2) la estructura procesal; y, 3) una política amplia de diversificación de respuestas y desestimación de casos. ${ }^{12}$

En cuanto al reforzamiento del debido proceso, Duce señala que para los adolescentes ello se traduce en "el fortalecimiento de la libertad y mayores restricciones a su privación en el proceso; exigencias más estrictas respecto a la extensión temporal del proceso; mayores resguardos al derecho de defensa (en diversas manifestaciones); y, exigencias más estrictas para la renuncia de derechos del debido proceso". "Así, por ejemplo, el uso de la detención preventiva debe estar particularmente limitado respecto de los jóvenes.

Con respecto a la generación de una política más amplia de diversificación de respuestas y desestimación de casos, en su argumentación este autor destaca el fundamento criminológico tras esta necesaria mayor amplitud, esto es, la importancia de evitar en la mayor medida posible el ingreso de los adolescentes al sistema penal considerando los impactos negativos, estigmatizadores y criminogénicos, que ello produciría en sus vidas. ${ }^{14}$

\footnotetext{
${ }^{10}$ COUSO, "La política criminal para adolescentes", cit. nota ${ }^{\circ} 9$, pp. 55-56.

${ }^{11}$ COUSO, "La política criminal para adolescentes", cit. nota ${ }^{\circ}$ 9, pp. 64-72.

${ }^{12}$ DUCE, Mauricio, "El derecho a un juzgamiento especializado de los jóvenes infractores en el derecho internacional de los derechos humanos y su impacto en el diseño del proceso penal juvenil", Revista Ius et Praxis $\mathrm{N}^{\circ}$ 1, Año 15 (2009), p. 77.

${ }^{13}$ DUCE, "El derecho a un juzgamiento especializado de los jóvenes infractores en el derecho internacional", cit. nota $\mathrm{n}^{\circ} 12$, pp. 84 y 85 .

${ }^{14}$ DUCE, "El derecho a un juzgamiento especializado de los jóvenes infractores en el derecho internacional”, cit. nota $\mathrm{n}^{\circ} 12$, p. 113.
} 
BERRÍOS, Gonzalo. "La ley de responsabilidad penal del adolescente como sistema de justicia: análisis y propuestas".

Si se tiene en cuenta la razón anterior sería posible introducir un matiz entre los fines considerados para los adolescentes y los fines previstos para los adultos relativos al uso de estos mecanismos procesales. Para los adultos el motivo principal de su aplicación sería diferente:"en una porción importante estas instituciones [mecanismos de desestimación y salidas alternativas] no apuntan como eje central al beneficio del imputado sino más bien a los efectos positivos para el sistema (vgr. descongestión del sistema)". ${ }^{15}$ Si bien no puede negarse que la racionalización de los recursos también es un objetivo de la justicia juvenil, el argumento se traduce en que si a ello sumamos consideraciones en torno al efecto sobre el adolescente ("consideración de la incidencia en su vida futura" de acuerdo con el art. 35 LRPA), es de esperar que el sistema funcione aplicando con mayor intensidad las herramientas de diversion.

Profundizando lo anterior, se concluye identificando tres hipótesis de diversificación de respuestas y desestimación de casos en la lógica del derecho internacional de los derechos humanos aplicable a los niños: 1) remisión o desestimación no condicionada previa a la intervención judicial; 2) remisión o desestimación con medidas o condiciones antes de la intervención judicial; y, 3) remisión o desestimación una vez producida la intervención judicial. $^{16}$

Por último, con el objeto de establecer las bases de un "modelo jurídico de responsabilidad", Cillero extrae de la Convención sobre los Derechos del Niño las proposiciones que permitirían organizar el sistema de justicia juvenil de una manera adecuada a las obligaciones previstas por aquella. Desde nuestra perspectiva, para este autor serían ocho los elementos clave que emanan de la CDN en materia de justicia penal: 1) consideración del niño como sujeto de derechos y con responsabilidad progresiva; 2) atribución de responsabilidad por participación en un hecho punible; 3) principio de legalidad penal; 4) aplicación del principio de oportunidad y de fórmulas de remisión del procedimiento como regla general; 5) aplicación intensiva de las garantías penales y procesales; 6) dignidad personal, integración social y responsabilidad como principios fundamentales de las consecuencias jurídicas aplicables; 7) reconocimiento de la naturaleza restrictiva de derechos de las sanciones; y, 8) regulación estricta del uso, duración y condiciones de la privación de libertad. ${ }^{17}$

Dentro de estos planteamientos un aporte adicional a lo que hemos venido revisando dice relación con la finalidad de las sanciones. Las consecuencias jurídicas deben "fortalecer el respeto del joven por las reglas de convivencia social fundadas en el respeto de los derechos de las demás personas (...) tiene que recibir un tipo de consecuencia que promueva su sentido de respeto a la convivencia social". ${ }^{18}$ Además, como buscar promover la integración social implica, a la vez, que las sanciones no han de ser desocializadoras ni

\footnotetext{
${ }^{15}$ DUCE, "El derecho a un juzgamiento especializado de los jóvenes infractores en el derecho internacional", cit. nota $\mathrm{n}^{\circ} 12$, p. 113 .

${ }^{16}$ DUCE, "El derecho a un juzgamiento especializado de los jóvenes infractores en el derecho internacional", cit. nota $\mathrm{n}^{\circ} 12$, pp. 115 y ss.

${ }^{17}$ CILLERO, Miguel, “Adolescentes y sistema penal. Proposiciones desde la Convención sobre los Derechos del Niño", Revista Justicia y Derechos del Niño N² (2000), pp. 101-138.

${ }^{18}$ CILLERO, “Adolescentes y sistema penal", cit. nota ${ }^{\circ} 17$, p. 129.
} 
Polít. crim. Vol. 6, № 11 (Junio 2011), Art. 6, pp. 163-191.

[http://www.politicacriminal.cl/Vol_06/n_11/Vol6N11A6.pdf]

despersonalizantes, ellas han de estar "destinadas únicamente a favorecer en los adolescentes el comportamiento conforme a derecho y evitar que la intervención -punitiva o educativa- del Estado se transforme en una instancia de profundización del daño y la marginación de la vida social". ${ }^{19}$

\section{Objetivos de la justicia penal juvenil}

Finalizada esta primera aproximación, en lo que sigue definiremos los objetivos del sistema penal de adolescentes que serán analizados con la información cuantitativa disponible, dejando para otra oportunidad el estudio del objetivo de reforzamiento del debido proceso. ${ }^{20}$ Sin embargo, antes de seguir adelante se debe aclarar que, ni desde nuestra perspectiva ni, según entendemos, desde la de los autores mencionados más arriba, se pretende sostener que la LRPA efectivamente represente total mente una ley adecuada a los principios de la $\mathrm{CDN},{ }^{21}$ incluso considerando el razonable margen de apreciación nacional que le cabe en su elaboración al legislador democrático. De ahí que, como ya indicamos, el diseño legal juega un papel importante en las posibilidades efectivas de la justicia juvenil de cumplir con ciertos fines.

Para los efectos de este estudio estableceremos cinco objetivos de la justicia penal para adolescentes, cuyo cumplimiento será objeto de análisis y valoración.

\subsection{Objetivo transversal: diferenciación del sistema penal de adultos}

Este objetivo o principio general de la justicia juvenil está asociado a que nos encontramos ante un derecho penal especial para adolescentes que, desde el punto de vista del funcionamiento práctico de la justicia de adultos y de adolescentes, se tiene que manifestar en un tratamiento diferenciado de los casos por parte de ambos sistemas. Si ya en sí misma la CDN expresa esta idea de especialidad, el art. 40.3 viene a reforzarla en materia de justicia penal al señalar que los Estados deben "promover el establecimiento de leyes, procedimientos, autoridades e instituciones específicos para los niños de quienes se alegue

${ }^{19}$ CILLERO, “Adolescentes y sistema penal”, cit. nota ${ }^{\circ} 17$, p. 134. En sentido similar señala Albrecht que "el único objetivo defendible constitucionalmente del derecho penal de menores es la dirección parcial del comportamiento en el sentido de la exigencia de comportamiento legal. Desde una perspectiva científico social esto último no es 'educación' (socialización), sino exclusivamente control social". ALBRECHT, PeterAlexis, "Respecto del futuro del derecho penal de menores -peligros y chances-", en: BUSTOS RAMÍREZ, Juan (Dir.), Un derecho penal del menor, Santiago: Ed. Jurídica Cono Sur, 1992, p. 63.

${ }^{20}$ Respecto de lo cual existe el acabado estudio efectuado por Mauricio Duce, cit. en nota $\mathrm{n}^{\circ} 12$.

${ }^{21}$ Así, se ha afirmado que "la ley no logra consolidar un sistema de reemplazo adecuado a la normativa internacional sobre derechos humanos", CILLERO, Miguel, "Ley N²0.084 sobre Responsabilidad Penal de Adolescentes", Anuario de Derechos Humanos 2006, p. 195; indirectamente y de forma más matizada, también Couso se muestra crítico al señalar que, tras la reforma introducida por la Ley $\mathrm{N}^{\circ}$ 20.191, "esta lectura [de un derecho penal mínimo de adolescentes que, entre otras fuentes, se basa en la CDN] no necesariamente expresa un acuerdo político amplio y profundo", COUSO, "La política criminal para adolescentes", cit. nota $n^{\circ} 9$, p. 48; y, por último, que en la Ley 20.084 "todavía se está bastante lejos de contener un sistema que reconozca y haya desarrollado en profundidad los elementos de especialidad procesal que requeriría un sistema de responsabilidad juvenil de acuerdo a los estándares desarrollados por el derecho internacional de los derechos humanos", DUCE, Mauricio, "El derecho a un juzgamiento especializado de los jóvenes infractores en el nuevo proceso penal juvenil chileno", Política Criminal Vol. 5, N 10 (2010), p. 336, http://www.politicacriminal.cl/Vol_05/n_10/Vol5N10A1.pdf 
BERRÍOS, Gonzalo. "La ley de responsabilidad penal del adolescente como sistema de justicia: análisis y propuestas".

que han infringido las leyes penales o a quienes se acuse o declare culpables de haber infringido esas leyes" (las cursivas son nuestras). Alcanzar esta diferenciación o especialidad es un objetivo transversal que marcará en buena medida la dirección de sentido de los otros objetivos identificados como centrales, pues implica que quienes tienen el poder de tomar decisiones dentro de la justicia juvenil efectivamente lo ejerzan considerando las diferencias de quienes serán afectados por ellas.

\subsection{Primer objetivo: privilegio de la desjudicialización y de las alternativas a la sanción penal}

La justicia penal juvenil debe operar privilegiando el "no contacto" del adolescente con ella misma y, de no ser posible, poniendo rápido término al proceso penal con alguna salida alternativa al juicio. Esta directriz está establecida en el art. 40.3.b) CDN cuando señala que se evitará recurrir a los procedimientos judiciales cuando ello sea apropiado y deseable, respetando en plenitud los derechos humanos y las garantías legales del niño.

Como ya se tuvo oportunidad de mencionar, el fundamento particular de este primer objetivo es evitar o mitigar los efectos desocializadores producidos al relacionar a un joven con el sistema penal, sin perjuicio de servir también a la descongestión de la administración de justicia.

Confirmando las principales contribuciones de los teóricos del etiquetamiento, como las de Lemert o Becker, un estudio reciente de Bernburg y Krohn demuestra los efectos negativos sobre los jóvenes producto de muchas de las intervenciones oficiales de la justicia penal, que terminan por aumentar la probabilidad de nuevas actividades delictivas de los sujetos estigmatizados. $^{22}$ A conclusiones similares arribaron Sampson y Laub, para quienes los contactos con el sistema penal forman parte del proceso de "acumulación de desventajas" de los infractores que, al debilitar aún más sus vínculos sociales, favorecen la continuación o persistencia en el delito. ${ }^{23}$ Por último, en el marco del Edinburgh Study of Youth Transitions and Crime, se ha evidenciado que las estrategias desjudicializadoras facilitan también los procesos de desistimiento del delito de los jóvenes. ${ }^{24}$ La desjudicialización, por tanto, no sólo evita los efectos negativos del contacto con el sistema punitivo, sino que a su vez genera efectos positivos respecto del control del delito.

\subsection{Segundo objetivo: privilegio de las sanciones no privativas de libertad}

Si es declarada la responsabilidad penal de un adolescente, como regla general se deben aplicar sanciones que no institucionalicen en centros cerrados a los jóvenes, pues, como

\footnotetext{
${ }^{22}$ Véase al respecto a BERNBURG, Jön Gunnar; KROHN, Marvin D., "Labeling, life chances, and adult crime: effects of official intervention in adolescence on crime in early adulthood", Criminology $\mathrm{N}^{\circ} 4$, Vol. 41, 2003, pp. 1287-1318; y a PETROSINO, Anthony; TURPIN-PETROSINO, Carolyn; GUCKENBURG, Sarah, "Formal System Processing of Juveniles: Effects on Delinquency", Campbell Systematic Reviews 2010:1, DOI: $10.4073 /$ csr.2010.1.

${ }^{23}$ SAMPSON, Robert J.; LAUB, John H., "A life-course theory of cumulative disadvantage and the stability of delinquency", en: THORNBERRY, Terence (Ed.), Developmental Theories of Crime and Delinquency, Advances in Criminological Theory Vol. 7, New Brunswick: Transaction Publishers, 1997, pp. 138-162.

${ }^{24}$ McARA, Lesley y McVIE, Susan, "Youth crime and justice: key messages from the Edinburgh Study of Youth Transitions and Crime", Criminology \& Criminal Justice 10 (2), 2010, pp. 197 y ss.
} 
veremos más adelante, la privación de libertad siempre ha de ser una reacción de carácter excepcional. Para concretar este principio, la CDN en el art. 40.4 favorece la existencia de "diversas medidas" y "alternativas a la internación en instituciones" en las legislaciones y prácticas de los Estados, como son, por ejemplo: libertad asistida o vigilada, servicios en beneficio de la comunidad, órdenes de orientación y supervisión, sanciones económicas o reparación del daño. ${ }^{25}$

\subsection{Tercer objetivo: legalidad, excepcionalidad y brevedad de la privación de libertad cautelar y sancionatoria}

De acuerdo con la regulación prevista en el art. 37 de la CDN, la privación de libertad sólo puede decretarse en los casos que la ley expresamente señala y por una autoridad debidamente facultada para ello. Por su parte, sólo debe cumplirse en lugares con ciertas condiciones especiales: separación de los adultos, consideración de sus necesidades particulares y satisfacción de sus derechos fundamentales, como la educación y la salud, "para así asegurarse de que la detención a la que los niños están sujetos no destruirá sus proyectos de vida". ${ }^{26}$

Un aspecto destacable de la $\mathrm{CDN}$ es la fijación de dos estándares particularmente relevantes y distintivos de la justicia juvenil en torno a la privación de libertad: "la detención, el encarcelamiento o la prisión de un niño (...) se utilizará tan sólo como medida de último recurso y durante el período más breve que proceda" (art. 37 letra b), esto es, el encierro de personas menores de dieciocho años de edad tiene restricciones especiales en cuanto a su uso (excepcionalidad) y a su duración (brevedad), limitaciones que se aplican a toda forma de privación de libertad, cualquiera sea su naturaleza jurídica o la persona facultada para ejecutarla u ordenarla.

Las razones materiales de estos estándares son expuestos con claridad en una sentencia del Tribunal Constitucional Federal alemán referida a la privación de libertad de los menores de edad:

"El encarcelamiento tiene en los menores una repercusión de especial calado. Su percepción del tiempo es diferente a la de las personas de más edad. Por lo general sufren más con la separación de su entorno social familiar y al verse abocados a estar solos. Sus personalidades están menos formadas que las de los adultos, y por ello están más abiertos al desarrollo. En consecuencia, esto crea necesidades especiales, oportunidades y amenazas singulares para el desarrollo posterior y una sensibilidad especial hacia el encarcelamiento, así como sensibilidad ante los efectos posiblemente negativos de la implementación de la pena de cárcel...La implementación de la pena de prisión, destinada a reconocer la dignidad humana y el principio de proporcionalidad, ha de tomar en cuenta dichas circunstancias (...)". 27

\footnotetext{
${ }^{25}$ Otros ejemplos de sanciones no privativas de libertad pueden encontrarse en las Reglas de las Naciones Unidas para la Administración de la Justicia de Menores ("Reglas de Beijing"), $\mathrm{N}^{\circ}$ 18, y en las Reglas Mínimas de las Naciones Unidas sobre las Medidas No Privativas de la Libertad ("Reglas de Tokio"), N 8.2. ${ }^{26}$ Corte Interamericana de Derechos Humanos, caso “Instituto de Reeducación del Menor 'Panchito López' v. Paraguay”, sentencia de 2 de septiembre de 2004, párr. 161.

27 Citado en DÜNKEL, Frieder; VAN ZYL SMIT, Dirk, "Implementación del encarcelamiento juvenil y derecho constitucional en Alemania”, en: SERRANO MAÍlLO, Alfonso; GUZMÁN DÁLBORA, José Luis
} 
BERRÍOS, Gonzalo. "La ley de responsabilidad penal del adolescente como sistema de justicia: análisis y propuestas".

2.5. Cuarto objetivo: favorecer la conducta conforme a derecho, promover la integración social de los adolescentes y evitar la reincidencia delictiva

Aun cuando la finalidad preventivo-especial positiva es ampliamente reconocida como la tarea principal de la justicia juvenil, ello no obsta a que sea uno de sus aspectos más debatidos y polémicos, tanto por el contenido que ha de asignársele y los límites que debe respetar, como por sus implicancias para la praxis del sistema. ${ }^{28}$ Más allá de esta importante discusión, cuyos alcances exceden al propósito de este estudio, la Ley se propone alcanzar tal objetivo y requiere ser evaluado.

Sin embargo, sólo será analizada una de sus posibles dimensiones, cual es la de evitar la reincidencia delictiva de los adolescentes. Esta decisión se funda, primero, en que contamos con los resultados de un estudio nacional sobre reincidencia juvenil y, segundo, porque es un método bastante común de evaluación de la eficacia de las sanciones. Para un análisis más amplio hay limitaciones de información, por ejemplo, sobre si se mejoraron, mantuvieron o empeoraron las condiciones de inclusión/exclusión social de los jóvenes, o el grado de satisfacción de los derechos garantizados a los condenados.

\section{Evaluación del cumplimiento de los objetivos}

\subsection{Antecedentes generales del sistema penal juvenil}

En forma previa al desarrollo del análisis del nivel de cumplimiento de los objetivos de la justicia penal juvenil, presentaremos algunos datos generales del sistema que nos servirán para contextualizar su funcionamiento. Para ello revisaremos información sobre el volumen de los adolescentes imputados, ${ }^{29}$ los delitos por los cuales son denunciados y posteriormente llevados ante un tribunal, y las diferencias que presentan por grupos etarios y por género.

(Eds.), Procesos de infracción de normas y de reacción a la infracción de normas: dos tradiciones criminológicas. Nuevos estudios en homenaje al profesor Alfonso Serrano Gómez, Madrid: Dykinson, 2008, p. 214. La sentencia es del 31 de mayo de 2006, BVerfG (2006) 2 BvR 1673/04-2 BvR 2402/04.

${ }^{28} \mathrm{Cfr}$. sobre este tema, entre muchos otros, ALBRECHT, Peter Alexis, El derecho penal de menores, Trad. BUSTOS RAMÍREZ, Juan, Barcelona: PPU, 1990, en especial, cap. 8 "El discutible principio directriz de la “educación'”, pp. 93-103; BUSTOS RAMÍREZ, Juan, Derecho penal del niño-adolescente, EJS, Santiago, 2007, pp. 26 y 68; CILLERO, Miguel, "La responsabilidad penal de adolescentes y el interés superior del niño", Revista Justicia y Derechos del Niño N 7, 2005, pp. 97-103; COUSO, Jaime, "Principio educativo y (re) socialización en el derecho penal juvenil", Revista Justicia y Derechos del Niño N ${ }^{\circ} 8$ (2006), pp. 51-63; CRUZ MÁRQUEZ, Beatriz, Educación y prevención general en el derecho penal de menores, Madrid: Marcial Pons, 2006, en particular, cap.1 "El principio educativo en el derecho penal juvenil”, pp. 21-60; y, VALENZUELA, Jonathan, "La pena y la educación. Una aproximación al fundamento de la pena juvenil", Revista de Estudios de la Justicia $\mathrm{N}^{\circ}$ 11, 2009, pp. 235-261.

${ }^{29} \mathrm{Se}$ debe tener presente que las instituciones registran como diferentes ingresos todas las ocasiones en que una misma persona es denunciada, detenida o atendida. Por ende, las cifras no se refieren a individuos. 
Polít. crim. Vol. 6, No 11 (Junio 2011), Art. 6, pp. 163-191.

[http://www.politicacriminal.cl/Vol_06/n_11/Vol6N11A6.pdf]

Tabla 1 Adolescentes ingresados al Ministerio Público 2008-2009-2010

\begin{tabular}{|l|c|c|c|c|c|c|}
\hline REGIÓN & 2008 & $\%$ & 2009 & $\%$ & 2010 & $\%$ \\
\hline Arica-Parinacota & 738 & $1,04 \%$ & 659 & $1,13 \%$ & 726 & $1,36 \%$ \\
\hline Tarapacá & 1406 & $1,99 \%$ & 1413 & $2,41 \%$ & 1330 & $2,49 \%$ \\
\hline Antofagasta & 3397 & $4,80 \%$ & 2406 & $4,11 \%$ & 2570 & $4,81 \%$ \\
\hline Atacama & 1902 & $2,69 \%$ & 1579 & $2,70 \%$ & 1536 & $2,87 \%$ \\
\hline Coquimbo & 3202 & $4,53 \%$ & 2389 & $4,08 \%$ & 2137 & $4,00 \%$ \\
\hline Valparaíso & 6988 & $9,88 \%$ & 6383 & $10,90 \%$ & 6104 & $11,42 \%$ \\
\hline O'Higgins & 3464 & $4,90 \%$ & 2772 & $4,74 \%$ & 2466 & $4,62 \%$ \\
\hline Maule & 4006 & $5,66 \%$ & 3061 & $5,23 \%$ & 2390 & $4,47 \%$ \\
\hline Bíobío & 8051 & $11,38 \%$ & 6179 & $10,55 \%$ & 4777 & $8,94 \%$ \\
\hline La Araucanía & 4134 & $5,84 \%$ & 3352 & $5,73 \%$ & 2915 & $5,46 \%$ \\
\hline Los Ríos & 1574 & $2,22 \%$ & 1311 & $2,24 \%$ & 1161 & $2,17 \%$ \\
\hline Los Lagos & 3447 & $4,87 \%$ & 2982 & $5,09 \%$ & 2629 & $4,92 \%$ \\
\hline Aysén & 569 & $0,80 \%$ & 469 & $0,80 \%$ & 511 & $0,96 \%$ \\
\hline Magallanes & 605 & $0,85 \%$ & 536 & $0,92 \%$ & 435 & $0,81 \%$ \\
\hline Metropolitana & 27278 & $38,55 \%$ & 23051 & $39,38 \%$ & 21741 & $40,69 \%$ \\
\hline TOTAL & 70761 & $100,00 \%$ & 58542 & $100,00 \%$ & 53428 & $100,00 \%$ \\
\hline
\end{tabular}

Fuente: elaboración propia a partir de los datos del Boletín estadístico años 2008, 2009 y 2010, Ministerio Público, pp. 139,49 y 47 , respectivamente.

Como se aprecia de la Tabla 1 el número de adolescentes que ingresan anualmente al Ministerio Público viene progresivamente disminuyendo entre los años 2008 a 2010, en prácticamente todas las regiones del país. Sin perjuicio de la baja en términos absolutos, un cambio significativo se da en el peso específico respecto del total que muestran las regiones del Bíobío y Valparaíso, pues esta última se consolida en el segundo lugar nacional al cabo de tres años. Además, es particularmente llamativa la cifra de ingresos del año 2008, pues no guarda relación con las cifras de ingresos de la Defensoría Penal Pública ni con el total de delitos ingresados el mismo año al propio Ministerio Público.

Para aproximarnos a la cantidad de adolescentes que efectivamente toman contacto con los tribunales de justicia son útiles los datos de la Defensoría, pues toda persona que carece de abogado es defendida por dicha institución en la primera audiencia judicial. Según estas cifras el año 2008 fueron atendidos 31.354 adolescentes, el 2009, 33.318 y el año 2010, $30.662,{ }^{30}$ lo que equivale a un 44,3\%, 56,9\% y 57,4\% de los ingresos al Ministerio Público durante los respectivos años.

Si comparamos los ingresos de jóvenes a la Defensoría con los de adultos, puede observarse que los adolescentes sólo representan alrededor de una décima parte del total de ingresos: $10,5 \%, 10,3 \%$ y 9,6\% para los años 2008, 2009 y 2010, respectivamente. Tales datos son ilustrativos del hecho de que la criminalidad adolescente no representa un fenómeno particularmente masivo comparado con la delincuencia adulta.

\footnotetext{
${ }^{30}$ Defensoría Penal Pública, “Informe estadístico anual 2010”, p. 24.
} 
BERRÍOS, Gonzalo. "La ley de responsabilidad penal del adolescente como sistema de justicia: análisis y propuestas".

En cuanto a la categoría de delitos por los cuales ingresan los jóvenes al Ministerio Público, se puede apreciar en la Tabla 2 que se trata mayoritariamente de faltas, lesiones y hurtos, presentando los dos primeros grupos una moderada tendencia al alza. Aunque en general los delitos tienden a representar una proporción similar del total durante todos los años, se aprecia una tendencia significativa a la baja en los delitos de robos $(10,19 \%$ a $7,42 \%)$.

Tabla 2 Delitos por categoría ingresados al Ministerio Público 2008-2009-2010

\begin{tabular}{|l|c|c|c|}
\hline CATEGORÍA DE DELITOS & 2008 & 2009 & 2010 \\
\hline Robos & $10,19 \%$ & $9,17 \%$ & $7,42 \%$ \\
\hline Robos No Violentos & $8,54 \%$ & $8,82 \%$ & $8,21 \%$ \\
\hline Hurtos & $13,92 \%$ & $14,19 \%$ & $13,66 \%$ \\
\hline Otros delitos contra la propiedad & $8,39 \%$ & $8,75 \%$ & $8,97 \%$ \\
\hline Lesiones & $13,49 \%$ & $13,71 \%$ & $14,87 \%$ \\
\hline Homicidios & $0,29 \%$ & $0,35 \%$ & $0,33 \%$ \\
\hline Delitos sexuales & $1,69 \%$ & $1,74 \%$ & $2,02 \%$ \\
\hline Contra la libertad e intimidad & $8,67 \%$ & $8,44 \%$ & $8,98 \%$ \\
\hline Faltas & $20,39 \%$ & $20,96 \%$ & $22,14 \%$ \\
\hline Ley de Tránsito & $0,46 \%$ & $0,38 \%$ & $0,49 \%$ \\
\hline Ley de Drogas & $1,84 \%$ & $1,89 \%$ & $1,92 \%$ \\
\hline Económicos & $0,47 \%$ & $0,51 \%$ & $0,46 \%$ \\
\hline Funcionarios & $0,01 \%$ & $0,02 \%$ & $0,02 \%$ \\
\hline Leyes especiales & $1,17 \%$ & $1,33 \%$ & $1,31 \%$ \\
\hline Contra la fe pública & $0,18 \%$ & $0,18 \%$ & $0,23 \%$ \\
\hline Cuasidelitos & $0,28 \%$ & $0,29 \%$ & $0,25 \%$ \\
\hline Otros delitos & $9,92 \%$ & $9,29 \%$ & $8,73 \%$ \\
\hline TOTAL & 55629 & 55600 & 50410 \\
\hline
\end{tabular}

Fuente: elaboración propia a partir de los datos del Boletín estadístico años 2008, 2009 y2010, Ministerio Público, pp.137, 47 y 45.

Un problema de los datos por categorías es que no permiten observar las tendencias particulares de cada tipo de delito, hecho que es especialmente restrictivo en información en categorías como la de "robos", que incluyen desde los robos calificados a los robos por sorpresa, delitos de una gravedad muy diferente entre sí. Una mirada más profunda sobre los delitos cometidos por adolescentes se puede obtener con cifras desagregadas, como en la Tabla 3.

Tabla 3 Los quince delitos más frecuentes según año y ranking

\begin{tabular}{|c|l|c|c|c|c|c|c|c|c|}
\hline \multirow{2}{*}{$\mathrm{N}^{\circ}$} & \multirow{2}{*}{ Delitos } & \multicolumn{2}{|c|}{$1^{\circ}$ año } & \multicolumn{2}{c|}{$2^{\circ}$ año } & \multicolumn{2}{c|}{$3^{\circ}$ año } & \multicolumn{2}{c|}{ Total } \\
\cline { 3 - 10 } & & $\mathrm{N}^{\circ}$ & $\%$ & $\mathrm{~N}^{\circ}$ & $\%$ & $\mathrm{~N}^{\circ}$ & $\%$ & $\mathrm{~N}^{\circ}$ & $\%$ \\
\hline 1 & Hurto simple & 5600 & $19,5 \%$ & 6180 & $19,2 \%$ & 6508 & $19,9 \%$ & 18288 & $19,5 \%$ \\
\hline 2 & Robo con intimidación & 2946 & $10,3 \%$ & 2445 & $7,6 \%$ & 2175 & $6,6 \%$ & 7566 & $8,1 \%$ \\
\hline 3 & Robo por sorpresa & 2136 & $7,5 \%$ & 2157 & $6,7 \%$ & 1725 & $5,3 \%$ & 6018 & $6,4 \%$ \\
\hline 4 & Robo en lugar no habitado & 1916 & $6,7 \%$ & 1907 & $5,9 \%$ & 1963 & $6,0 \%$ & 5786 & $6,2 \%$ \\
\hline 5 & Receptación & 1459 & $5,1 \%$ & 1892 & $5,9 \%$ & 2266 & $6,9 \%$ & 5617 & $6,0 \%$ \\
\hline
\end{tabular}


Polít. crim. Vol. 6, № 11 (Junio 2011), Art. 6, pp. 163-191. [http://www.politicacriminal.cl/Vol_06/n_11/Vol6N11A6.pdf]

\begin{tabular}{|c|l|c|c|c|c|c|c|c|c|}
6 & Robo con violencia & 1884 & $6,6 \%$ & 1816 & $5,6 \%$ & 1666 & $5,1 \%$ & 5366 & $5,7 \%$ \\
\hline 7 & $\begin{array}{l}\text { Robo en lugar habitado o } \\
\text { destinado a la habitación }\end{array}$ & 1721 & $6,0 \%$ & 1714 & $5,3 \%$ & 1580 & $4,8 \%$ & 5015 & $5,4 \%$ \\
\hline 8 & $\begin{array}{l}\text { Robo en bienes nacionales } \\
\text { de uso público }\end{array}$ & 1349 & $4,7 \%$ & 1535 & $4,8 \%$ & 1628 & $5,0 \%$ & 4512 & $4,8 \%$ \\
\hline 9 & Porte de arma (288 bis) & 1254 & $4,4 \%$ & 1381 & $4,3 \%$ & 1436 & $4,4 \%$ & 4071 & $4,3 \%$ \\
\hline 10 & Daños simples & 1056 & $3,7 \%$ & 1391 & $4,3 \%$ & 1325 & $4,0 \%$ & 3772 & $4,0 \%$ \\
\hline 11 & Amenazas & 773 & $2,7 \%$ & 1142 & $3,5 \%$ & 1178 & $3,6 \%$ & 3093 & $3,3 \%$ \\
\hline 12 & Lesiones menos graves & 725 & $2,5 \%$ & 1119 & $3,5 \%$ & 1242 & $3,8 \%$ & 3086 & $3,3 \%$ \\
\hline 13 & Hurto falta (494 bis) & 712 & $2,5 \%$ & 877 & $2,7 \%$ & 970 & $3,0 \%$ & 2559 & $2,7 \%$ \\
\hline 14 & Lesiones leves & 632 & $2,2 \%$ & 841 & $2,6 \%$ & 1052 & $3,2 \%$ & 2525 & $2,7 \%$ \\
\hline 15 & $\begin{array}{l}\text { Porte ilegal de arma de } \\
\text { fuego, municiones y otros }\end{array}$ & 596 & $2,1 \%$ & 574 & $1,8 \%$ & 629 & $1,9 \%$ & 1799 & $1,9 \%$ \\
\hline 16 & Otros & 3912 & $13,6 \%$ & 5233 & $16,2 \%$ & 5426 & $16,6 \%$ & 14571 & $15,6 \%$ \\
\hline \multicolumn{2}{|l|}{ TOTAL } & 28671 & $100 \%$ & 32204 & $100 \%$ & 32769 & $100 \%$ & 93644 & $100 \%$ \\
\hline
\end{tabular}

Fuente: BERRÍOS / VIAL, "3 años de vigencia", cit. nota n 32, Tabla 8, p. 22.

Como se puede ver sólo quince delitos representan un $84,4 \%$ de todas las infracciones registradas por la Defensoría, la mayor parte de ellos vinculados a la propiedad. Por otra parte, puede observarse que varios de los delitos presentan una tendencia a la baja, como los robos con intimidación, robos en lugar habitado y robos con violencia. Muestran una tendencia al alza, por su parte, las lesiones leves y menos graves, la receptación y las amenazas. Si bien no se cuenta con información de los adolescentes con causas de violencia intrafamiliar, una hipótesis para explicar el aumento de las lesiones y amenazas es que esté relacionado precisamente con la importancia que ha adquirido tal problema social. ${ }^{31}$ También pudiera explicarse por una mayor criminalización de los conflictos entre pares surgidos en torno a los recintos educacionales.

En materia de género, las mujeres adolescentes muestran una tasa de crecimiento entre el primer y tercer año de vigencia de la Ley de $25,9 \%$ frente al 11,6\% de los hombres. De esta manera, las mujeres aumentan su participación desde un $12,9 \%$ a un $14,4 \%$ del total de jóvenes imputados. ${ }^{32}$ Como ha sucedido en otros países es probable que continúe el aumento de la participación de las mujeres adolescentes en la justicia juvenil, aunque sin llegar a equiparar la participación masculina. ${ }^{33}$ En cuanto al tipo de delitos imputados, las adolescentes presentan rasgos distintivos: un $47,2 \%$ son hurtos, un $12,5 \%$ lesiones y un $7,1 \%$ faltas. $^{34}$

\footnotetext{
${ }^{31}$ En adultos, el 38,4\% de las lesiones y el 31,6\% de las amenazas están relacionadas con violencia intrafamiliar. Véase en Defensoría Penal Pública, "Informe 2010", cit. nota n 30, Tabla 84 y 85, pp. 91 y 92.

${ }^{32}$ BERRÍOS, Gonzalo; VIAL, Luis, "3 años de vigencia Ley de responsabilidad penal del adolescente. 8 de junio de 2007 a 7 de junio de 2010”, Defensoría Penal Pública -UNICEF, 2011, p. 6.

33 RUTTER, Michael; GILLER, Henri; HAGELL, Ann, La conducta antisocial de los jóvenes, Madrid: Cambridge University Press, 2000, p. 384; y VÁZQUEZ GONZÁLEZ, Carlos, Delincuencia juvenil. Consideraciones penales y criminológicas, Madrid: Ed. Colex, 2003, p. 43.

${ }^{34}$ Defensoría Penal Pública, "Informe 2010”, cit. nota n 30, Tabla 35, p. 55.
} 
Finalmente, en cuanto a la distribución por los grupos etarios de 14-15 y 16-17 años, las cifras varían según se trate de los ingresos al Ministerio Público o a la Defensoría Penal Pública. En promedio y en forma estable en los períodos de tiempo de referencia, en el primer caso los grupos etarios se distribuyen en $38 \%$ y $62 \%{ }^{35}$ y en el segundo en $26 \%$ y $74 \%$, respectivamente. ${ }^{36}$ Para explicar el cambio en la proporción faltan datos sobre tipo de delitos y formas de término utilizados. En todo caso, se confirma que a menor edad el problema tiende a disminuir.

\subsection{Primer objetivo: privilegio a la desjudicialización y a las alternativas a la sanción penal}

Un primer paso para analizar este objetivo es establecer si existen o no prácticas diferenciadas entre el sistema penal de adultos y el de adolescentes. De acuerdo con lo sostenido por Duce, existirían diferencias positivas en el funcionamiento de ambos sistemas, ya que las formas más relevantes de término de los casos se utilizarían con mayor frecuencia cuando los imputados son adolescentes. El principio de oportunidad se aplicaría más del doble que en adultos, la suspensión condicional del procedimiento casi duplicaría el porcentaje de los mayores de edad y los acuerdos reparatorios serían superiores en más de un $50 \% .{ }^{37}$ Un punto clave para llegar a esta lectura es que la base de cálculo empleada incluye el total de los términos, sin hacer distinción entre los casos con imputado conocido de los casos con imputado desconocido.

En nuestra opinión, es posible efectuar un análisis más preciso sobre la existencia o no de prácticas diferenciadas si se utiliza otra base de comparación. Como los adolescentes requieren ser "conocidos" para considerarlos como tales, la base de cálculo más adecuada para hacer comparaciones con los mayores de edad son precisamente los datos de imputados adultos "conocidos", excluyendo a los imputados "no conocidos".

Por lo demás, esta distinción es esencial, pues el comportamiento del órgano de persecución penal es muy distinto en una y otra situación. El 2010 el 47,82\% de los ingresos al Ministerio Público se catalogaron "sin imputado conocido", frente a los cuales las formas de término empleadas fueron fundamentalmente el archivo provisional $(82,81 \%)$-falta de antecedentes suficientes para desarrollar una investigación penal-, y la facultad para no investigar $(11,18 \%$ ) - hechos no constitutivos de delito o en los que la responsabilidad penal está extinguida-. ${ }^{38}$

En la Tabla 4 se comparan los distintos tipos de término de las causas de adolescentes y de adultos "conocidos".

\footnotetext{
${ }^{35}$ Ministerio Público, "Boletín estadístico" años 2008, 2009 y 2010, pp. 139, 49 y 47, respectivamente.

${ }^{36}$ BERRÍOS / VIAL, "3 años de vigencia", cit. nota n 32 , p. 7.

${ }^{37}$ Consúltese DUCE, "El derecho a un juzgamiento especializado de los jóvenes infractores en el nuevo proceso penal juvenil chileno", cit. nota ${ }^{\circ} 21$, pp. 328-335.

${ }^{38}$ Ministerio Público, "Boletín estadístico año 2010”, 2011, pp. 17 y 27, respectivamente.
} 
Polít. crim. Vol. 6, No 11 (Junio 2011), Art. 6, pp. 163-191.

[http://www.politicacriminal.cl/Vol_06/n_11/Vol6N11A6.pdf]

Tabla 4 Formas de término de adultos y adolescentes año 2010

\begin{tabular}{|c|c|c|}
\hline Tipo de término & Adulto & Adolescente \\
\hline Sentencia definitiva condenatoria & $27,77 \%$ & $29,05 \%$ \\
\hline Sentencia definitiva absolutoria & $0,82 \%$ & $0,89 \%$ \\
\hline Sobreseimiento definitivo & $4,36 \%$ & $3,94 \%$ \\
\hline Sobreseimiento temporal & $1,69 \%$ & $0,89 \%$ \\
\hline Suspensión condicional del procedimiento & $22,60 \%$ & $22,59 \%$ \\
\hline Acuerdo reparatorio & $2,68 \%$ & $2,47 \%$ \\
\hline Facultad para no investigar & $5,44 \%$ & $4,80 \%$ \\
\hline Subtotal salida judicial & $65,35 \%$ & $64,61 \%$ \\
\hline Archivo provisional & $18,31 \%$ & $13,09 \%$ \\
\hline Decisión de no perseverar & $4,40 \%$ & $3,64 \%$ \\
\hline Principio de oportunidad & $10,73 \%$ & $15,32 \%$ \\
\hline Incompetencia & $1,21 \%$ & $3,34 \%$ \\
\hline Subtotal salida no judicial & $34,65 \%$ & $35,39 \%$ \\
\hline TOTAL & $100 \%$ & $100 \%$ \\
\hline
\end{tabular}

Fuente: elaboración propia a partir de los datos del Boletín estadístico año 2010, Ministerio Público, pp. 27 y 46.

Las cifras permiten concluir que existe un funcionamiento bastante homogéneo de la justicia penal de adultos con la justicia juvenil, sin mayores diferencias en el trato otorgado a ambos grupos, lo cual es particularmente notorio en el uso de las salidas alternativas al proceso (suspensión condicional del procedimiento y acuerdos reparatorios). También llama la atención que las sentencias condenatorias sean porcentualmente más altas en los adolescentes que en los adultos. La única forma de término relevante donde se puede apreciar una diferencia significativa es el principio de oportunidad, aunque es difícil realizar una valoración concluyente sobre ello, pues aunque el porcentaje de adolescentes es superior, también es cierto que el art. 35 LRPA permite emplear este mecanismo en más casos que si se tratara de adultos.

Por otro lado, desde la perspectiva del comportamiento interno del sistema penal de adolescentes las tendencias respecto de este objetivo también son preocupantes. Así, si las salidas alternativas representaban durante el primer año de la Ley un $43 \%$ de las formas de término de las causas, al tercer año sólo alcanzan a un 33,1\%. En un sentido contrario, las condenas han evolucionado desde un $34,8 \%$ el primer año a un $44 \%$ el tercero. ${ }^{39}$

En definitiva, de estos antecedentes se puede concluir que el sistema no está funcionando de una forma distinta con los adolescentes en lo referido a las políticas de desjudicialización y de alternativas al juicio, pese a que debieran ser formas de término de los casos especialmente utilizadas en jóvenes infractores. Más grave aún es que actualmente las condenas son la forma de término más frecuente de la justicia juvenil,

${ }^{39}$ BERRÍOS / VIAL, “3 años de vigencia”, cit. nota $n^{\circ} 32$, p. 24. 
superando en más de un $10 \%$ el uso de las salidas alternativas. Las razones de ello no son evidentes y su esclarecimiento requiere de datos más detallados.

Una hipótesis explicativa dice relación con los niveles de reincidencia de los adolescentes, que por razones legales o de criterios de persecución penal restringiría las posibilidades de aplicación de ciertas alternativas. Otra hipótesis, relacionada en parte con la anterior, es que, dada la falta de especialidad en la regulación normativa de las salidas alternativas, en muchos casos éstas resultan de facto más gravosas que una sanción, por ejemplo, de amonestación, lo que llevaría a algunos imputados a preferirlas. Por último, no debe descartarse el peso de la falta de especialización en las instituciones y de las diferentes lecturas de los objetivos de la Ley que puedan estar afectando una política más intensa de desjudicialización. Ejemplo del primer caso es la poca aplicación del criterio de actuación del Ministerio Público que amplía su política en materia de suspensiones condicionales del procedimiento, la que no ha tenido un mayor impacto en la práctica; y ejemplo de lo segundo, el criterio de no propiciar la aplicación del principio de oportunidad "si existen antecedentes serios de que el adolescente, en función de su interés superior, requiere una intervención penal más intensa", política basada en una lectura "benéfica y educativa" de la intervención penal y en un concepto del interés superior del niño distinto del de protección y respeto de sus derechos. ${ }^{40}$

Naturalmente, todas estas posibles explicaciones, y su peso concreto en el fenómeno, no son excluyentes entre sí ni con toda seguridad son las únicas imaginables. Lo que no cambia, en todo caso, es el hecho de que cada vez se aplican menos salidas alternativas a los adolescentes con todos los efectos negativos que, según las investigaciones ya reseñadas, ello produce en la prevención de nuevos delitos.

\subsection{Segundo objetivo: privilegio de las sanciones no privativas de libertad}

Desde el punto de vista de la distribución de las sanciones aplicadas a los adolescentes, como se observa en la Tabla 5, el promedio de los tres primeros años de vigencia de la Ley fue de un $90,3 \%$ de sanciones no privativas de libertad y un 9,7\% de penas privativas de libertad (régimen cerrado, semicerrado y sanción mixta del art. 19 letra a), cifras que en una primera aproximación deben ser valoradas positivamente, pues expresan un efectivo privilegio del empleo de sanciones que no implican el encierro. El punto es que si son pocas las salidas alternativas en relación con las condenas, aunque las penas no privativas de libertad sean las más aplicadas, de todas maneras existe un problema de fondo por el recurso excesivo a las sanciones penales como respuesta a los delitos de los jóvenes.

\footnotetext{
${ }^{40}$ Ministerio Público, “Instrucción general que imparte criterios de actuación en materia de responsabilidad penal adolescente, Ley 20.084”, Oficio FN N ${ }^{\circ} 483 / 2009$, p. 10.
} 
Polít. crim. Vol. 6, No 11 (Junio 2011), Art. 6, pp. 163-191.

[http://www.politicacriminal.cl/Vol_06/n_11/Vol6N11A6.pdf]

Tabla 5 Clases de sanciones decretadas

\begin{tabular}{|l|c|c|c|c|c|c|c|c|}
\hline & \multicolumn{2}{|c|}{$1^{\circ}$ año } & \multicolumn{2}{c|}{$2^{\circ}$ año } & \multicolumn{2}{c|}{$3^{\circ}$ año } & \multicolumn{2}{c|}{ Total } \\
\cline { 2 - 10 } & Cantidad & $\%$ & Cantidad & $\%$ & Cantidad & $\%$ & Cantidad & $\%$ \\
\hline Internación régimen cerrado & 238 & $2,9 \%$ & 578 & $3,5 \%$ & 636 & $3,6 \%$ & 1452 & $3,4 \%$ \\
\hline Internación régimen semicerrado & 414 & $5,0 \%$ & 643 & $3,9 \%$ & 717 & $4,0 \%$ & 1774 & $4,2 \%$ \\
\hline Libertad asistida especial & 1752 & $21,2 \%$ & 3195 & $19,5 \%$ & 3338 & $18,9 \%$ & 8285 & $19,6 \%$ \\
\hline Libertad asistida & 1189 & $14,4 \%$ & 2295 & $14,0 \%$ & 2247 & $12,7 \%$ & 5731 & $13,5 \%$ \\
\hline $\begin{array}{l}\text { Servicios en beneficio de la } \\
\text { comunidad }\end{array}$ & 2461 & $29,7 \%$ & 5567 & $34,0 \%$ & 6583 & $37,2 \%$ & 14611 & $34,5 \%$ \\
\hline Reparación del daño causado & 25 & $0,3 \%$ & 28 & $0,2 \%$ & 23 & $0,1 \%$ & 76 & $0,2 \%$ \\
\hline Multa & 556 & $6,7 \%$ & 974 & $6,0 \%$ & 1095 & $6,2 \%$ & 2625 & $6,2 \%$ \\
\hline Amonestación & 1580 & $19,1 \%$ & 2688 & $16,4 \%$ & 2583 & $14,6 \%$ & 6851 & $16,2 \%$ \\
\hline Sanción mixta art. 19 letra a) & 61 & $0,7 \%$ & 368 & $2,3 \%$ & 439 & $2,5 \%$ & 868 & $2,1 \%$ \\
\hline Sanción mixta art. 19 letra b) & 4 & $0,0 \%$ & 14 & $0,1 \%$ & 44 & $0,2 \%$ & 62 & $0,1 \%$ \\
\hline TOTAL & 8280 & $100 \%$ & 16350 & $100 \%$ & 17705 & $100 \%$ & 42335 & $100 \%$ \\
\hline
\end{tabular}

Fuente: BERRÍOS/VIAL,“3 años de vigencia”, cit. nota n³ 32,Tabla 11, p. 27.

En todo caso, investigaciones posteriores debieran poder esclarecer más esta dimensión de la justicia juvenil introduciendo nuevas variables en el análisis, como el tipo de delito y la alternatividad penal concreta del caso según las reglas de determinación de la pena juvenil aplicables. Sería relevante conocer cómo se comporta el sistema en los casos donde se pone fuertemente en tensión el privilegio de las sanciones en medio libre y la excepcionalidad de la privación de libertad como, por ejemplo, cuando debe decidirse entre las alternativas de sanción previstas en el art. $23 \mathrm{~N}^{\circ} 2 \mathrm{LRPA}^{41}{ }^{41}$ en principio aplicable a robos con intimidación, con fuerza en lugar habitado y con violencia, homicidios simples, entre otros.

Por su parte, también es llamativo el hecho de que progresivamente se ha ido consolidando como la principal sanción no privativa de libertad la prestación de servicios en beneficio de la comunidad, aumentando su participación desde un $29,7 \%$ a un $37,2 \%$. Ambas clases de libertad asistida, en cambio, evolucionan desde un 35,6\% a un 31,6\%.En nuestra opinión, este mayor peso de los servicios comunitarios no guarda relación con la escasa regulación legal de dicha sanción y con la poca relevancia que se le ha dado no sólo en la academia, sino también en la propia entidad a cargo de la ejecución de las sanciones.

A partir de los datos sobre reparación del daño $(0,2 \%)$, multa $(6,2 \%)$ e internación en régimen semicerrado $(4,2 \%)$ hemos sostenido con anterioridad ${ }^{42}$ que ellos deben tenerse presentes al momento de estudiar eventuales cambios legislativos, pues en los hechos la

\footnotetext{
${ }^{41}$ Las sanciones aplicables en ese caso son: libertad asistida especial, internación en régimen semicerrado e internación en régimen cerrado, además de la sanción mixta del art. 19 letra a) LRPA.

${ }^{42}$ BERRÍOS / VIAL, "3 años de vigencia", cit. nota ${ }^{\circ} 32$, p. 41.
} 
BERRÍOS, Gonzalo. "La ley de responsabilidad penal del adolescente como sistema de justicia: análisis y propuestas".

alternatividad penal es más reducida que la prevista en la Ley -la reparación del daño prácticamente no se aplica- y las multas y la internación en régimen semicerrado representan en conjunto más de un $10 \%$ de las sanciones aplicadas. Su mera eliminación podría generar un impacto significativo en el tipo de sanciones que se decreten, tanto en las sentencias condenatorias, como en los quebrantamientos de condena. ${ }^{43}$

Con respecto a las sanciones privativas de libertad, abordaremos su análisis en el capítulo que sigue. Sólo adelantaremos que la tendencia al alza que muestran las estadísticas será motivo de una atención particular.

\subsection{Tercer objetivo: legalidad, excepcionalidad y brevedad de la privación de libertad cautelar y sancionatoria}

Sobre este objetivo analizaremos datos relativos a las detenciones policiales, la internación provisoria y la aplicación de la pena de internación en régimen cerrado, para lo que recurriremos a diversas fuentes estadísticas. Si bien no siempre ellas coinciden en los períodos de tiempo y, a veces, en las cifras mismas, de todos modos nos permitirán tener una visión confiable acerca de la privación de libertad aplicada a los adolescentes.

Con respecto a la detención policial, el volumen de adolescentes detenidos el 2009 por Carabineros de Chile alcanzó a 48.902, lo que equivale a un 9,3\% del total de personas detenidas durante ese año. ${ }^{44}$ Por edades, las detenciones se distribuyen en un $11,10 \%$ a los 14 años, $19,46 \%$ a los 15 años, 30,35\% a los 16 años y 39,07\% a los 17 años. Considerando los nueve principales delitos que originaron la detención, los hurtos en supermercados y centros comerciales representan un 18,63\%, los desórdenes públicos un 4,48\%, el robo con intimidación un 4,14\%, las lesiones leves un 5,12\%, los daños simples un 3,92\%, el robo con violencia un $3,82 \%$, el robo por sorpresa un $3,47 \%$, el hurto falta un $4,18 \%$, y el hurto simple (valor entre media y cuatro unidades tributarias mensuales) un 3,95\%. En cuanto a la distribución por género, los hombres representan un $82,9 \%$ y las mujeres un $17,1 \%$ de los detenidos. En el caso de la Policía de Investigaciones, también con datos del año 2009, un $50,8 \%$ de los 4.995 detenidos lo fue por delito flagrante, un $40,7 \%$ por orden de detención y un $5,2 \%$ por una orden verbal. Un $14 \%$ ellos fueron mujeres y un $86 \%$ hombres. $^{45}$

Por otro lado, de acuerdo con las cifras de la Defensoría los adolescentes ingresan mayoritariamente al sistema judicial en calidad de detenidos y en un porcentaje más alto que los adultos. Así, el 2009 un 72,5\% de los jóvenes ingresó a través de una audiencia de control de la detención (24.160), mientras que los adultos sólo lo hicieron en un 57,5\%. El

\footnotetext{
${ }^{43}$ Piénsese en el caso del quebrantamiento de la libertad asistida especial, que se sanciona con su sustitución por la sanción de internación en régimen semicerrado (art. $52 \mathrm{~N}^{\circ} 5 \mathrm{LRPA}$ ). De no existir esta última pena, la única consecuencia posible sería la internación en régimen cerrado.

${ }^{44}$ Véase BLANCO, Javiera, "Violencia y delincuencia juvenil: desafíos en relación con los programas y respuestas del sistema", Serie Conceptos $\mathrm{N}^{\circ}$ 18, Fundación Paz Ciudadana, 2010, p. 4.

${ }^{45}$ MARTÍNEZ, Jorge (coord.), "Informe de diagnóstico de la implementación de la Ley 20.084, junio 2007marzo 2010”, Servicio Nacional de Menores, 2010, pp. 9-13. Las cifras de Carabineros también contemplaban a los aprehendidos por orden judicial $(4,06 \%)$ los que, por no ser propiamente un delito, no fueron incluidos, a diferencia de la fuente citada.
} 
Polít. crim. Vol. 6, No 11 (Junio 2011), Art. 6, pp. 163-191.

[http://www.politicacriminal.cl/Vol_06/n_11/Vol6N11A6.pdf]

año 2010 la cifra alcanzó a un 68,4\% (20.960) y 54,8\%, respectivamente. ${ }^{46}$ En otro informe -sobre el primer año de funcionamiento de la Ley- se detectó que en la región metropolitana el porcentaje de adolescentes que ingresaban por una audiencia de control de la detención alcanzaba a cerca del $89 \%$, cifra por sobre el promedio nacional de $73,3 \% .{ }^{47} \mathrm{El}$ dato es interesante de considerar, pues es posible que la existencia de un complejo sistema de procesamiento de casos penales en torno al Centro de Justicia de Santiago, sea un factor favorecedor del uso de la detención como herramienta de política criminal. La prolongación de la detención hasta la audiencia es, en muchos casos, innecesaria ante una posible respuesta del sistema por la vía de la desjudicialización e, incluso, podría ser una razón más tras el aumento general de las condenas.

En cuanto a la aplicación de la medida cautelar de internación provisoria, la evolución de los tres primeros años de funcionamiento del sistema ha sido la siguiente: un $8,6 \%$ de uso el primer año, un $8,5 \%$ durante el segundo y un 7,5\% durante el tercer año, cifras calculadas sobre la base de los adolescentes con sus causas terminadas. ${ }^{48}$ En forma complementaria, los datos del Servicio Nacional de Menores (en adelante, SENAME) también muestran una positiva disminución en las cifras de los adolescentes "atendidos" en internación provisoria: 4.945 jóvenes en 2008, 4.688 adolescentes en 2009 y 4.099 durante el 2010. ${ }^{49}$ Asimismo, los jóvenes en internación provisoria que ingresaron dentro del año 2009 fueron 3.876 y el $2010,3.253 .^{50}$

En donde las cifras no permiten hacer una valoración favorable es en el hecho de que los tiempos promedio de duración de la internación provisoria han aumentado significativamente en estos años y a una tasa superior a la de adultos, como se aprecia en la Tabla 6. En tres años el tiempo promedio de la internación provisoria aumentó en 37,8 días y a una tasa de crecimiento de $46,5 \%$, mientras que en el caso de adultos la tasa de aumento fue de $30,6 \% .51$

Tabla 6 Comparación días en internación provisoria/prisión preventiva (media)

\begin{tabular}{|c|c|c|c|c|}
\hline & $1^{\circ}$ año & $2^{\circ}$ año & $3^{\circ}$ año & Total \\
\cline { 2 - 5 } & Media & Media & Media & Media \\
\hline Adolescentes & 81,1 & 99,6 & 118,9 & 100,7 \\
\hline Adultos & 96,8 & 110,9 & 126,4 & 110,8 \\
\hline
\end{tabular}

Fuente: BERRÍOS / VIAL, "3 años de vigencia", cit. nota n 32, Tabla 6, p. 16,

\footnotetext{
${ }^{46}$ Defensoría Penal Pública, "Informe 2010", cit. nota ${ }^{\circ} 30$, p. 43.

${ }^{47}$ Defensoría Penal Pública, "Primer año de vigencia Ley de responsabilidad penal adolescente (8 de junio de 2007 a 7 de junio de 2008)", 2009, p. 32.

${ }^{48}$ BERRÍOS / VIAL, “3 años de vigencia”, cit. nota ${ }^{\circ} 32$, p. 15 ,

${ }^{49}$ Servicio Nacional de Menores, "Boletín Estadístico Anual”, años 2008, 2009 y 2010, $\sin \mathrm{n}^{\circ}$ p.

${ }^{50}$ Este último cálculo se obtiene al restar los jóvenes vigentes al 31 de diciembre del año anterior al calculado, pues ellos se incluyen en las estadísticas del SENAME dentro de la categoría "atendidos" del año calculado. Por ejemplo, si el 31 de diciembre de 2009 habían 846 adolescentes vigentes y el año 2010 fueron atendidos 4.099, los ingresados entre enero y diciembre de 2010 se calculan restando a esta última cifra los vigentes del año anterior. Así se obtiene la cifra de 3.253.

${ }^{51}$ BERRÍOS / VIAL, "3 años de vigencia", cit. nota ${ }^{\circ} 32$, p. 16.
} 
BERRÍOS, Gonzalo. "La ley de responsabilidad penal del adolescente como sistema de justicia: análisis y propuestas".

Un punto asociado con la legalidad del uso de la internación provisoria es el grado de cumplimiento de la norma que exige que su uso sea proporcional con la probable sanción a imponer en el caso concreto (art. 33 LRPA). Para medir el cumplimiento de esta norma se toman como base los adolescentes a los cuales se les decretó la medida de internación provisoria y después se contrasta esta información con la forma de término del caso, que incluye todas las posibles opciones: sanciones impuestas en sentencias condenatorias, absoluciones y otras formas de término (por ejemplo, sobreseimiento definitivo, facultad de no perseverar, salidas alternativas).

Gráfico 1 Imputados con internación provisoria según forma de término de la causa

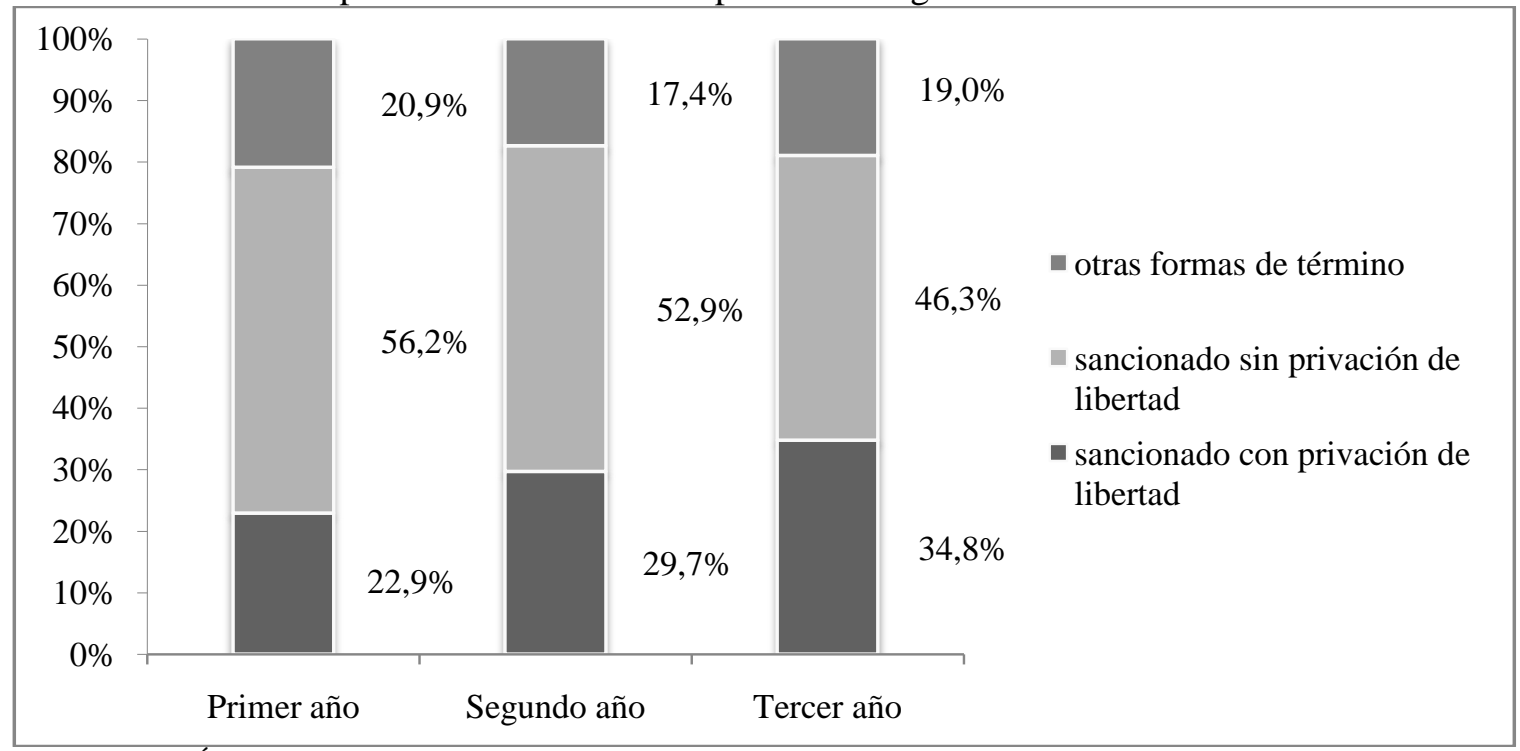

Fuente: BERRÍOS / VIAL, “3 años de vigencia”, cit. nota n 32, Gráfico 11, p. 17.

En un ejercicio conservador, pues asume como correcto que es proporcional una internación provisoria con una pena de internación en régimen semicerrado, ${ }^{52}$ las cifras presentadas en el Gráfico 1 indican que hay un severo problema con el respeto a la legalidad en el empleo de la internación provisoria, pues se vulnera en más de seis de cada diez casos la proporcionalidad de la medida con la sanción probable. Aunque en el total del período se observa una mejora progresiva, al tercer año aún un 65,2\% de los jóvenes en internación provisoria no es condenado a una pena privativa de libertad y dentro de este grupo, un $19 \%$ ni siquiera resulta finalmente condenado y sancionado. Si bien no contamos con datos actualizados, en el primer año de vigencia de la Ley se constató que un 89,2\% de los presos en forma provisoria no fue condenado a internación en régimen cerrado ${ }^{53}$-pena que es materialmente equivalente a la internación provisoria, no así la internación en régimen semicerrado-, por lo que, si se mantiene la relación entre las sanciones de régimen cerrado y semicerrado existente el primer año, se puede estimar que la vulneración al

\footnotetext{
${ }^{52}$ Hay jurisprudencia que sostiene que el régimen semicerrado no es una pena parcialmente privativa de libertad que sea desproporcionada con la mantención de la internación provisoria, por ejemplo, decisión del Tribunal de Juicio Oral en lo Penal de Valdivia, causa Rit 74-2008, 5 de septiembre de 2008, voto de mayoría. ${ }^{53}$ Defensoría Penal Pública: "Primer año de vigencia...", cit. nota n 47, p. 19.
} 
Polít. crim. Vol. 6, № 11 (Junio 2011), Art. 6, pp. 163-191.

[http://www.politicacriminal.cl/Vol_06/n_11/Vol6N11A6.pdf]

principio de proporcionalidad actualmente bordea el $86 \%^{54}$ de los casos en internación provisoria.

Por último, en relación con la aplicación de penas privativas de libertad, en el curso de tres años ha ido aumentando progresivamente la aplicación de esta clase de sanciones. De acuerdo con las cifras del SENAME, los "atendidos" en centros privativos de libertad para cumplir con la sanción de internación en régimen cerrado han evolucionado de la siguiente manera: 958 jóvenes en 2008, 1.351 en 2009 y 1.723 jóvenes en 2010. Por su parte, los jóvenes que ingresaron en internación en régimen cerrado dentro del año 2009 fueron 935 y en el 2010 un total de $1.158 .^{55}$

Tales datos coinciden con la tendencia que registra la Defensoría Penal Pública en los tipos de sanciones impuestas y que se puede observar en la Tabla 5 supra. Si se suman todas las sanciones privativas de libertad, esto es, en régimen cerrado, semicerrado y la sanción mixta del art. 19 letra a) LRPA, la tendencia ascendente de las mismas se ve nuevamente ratificada: el primer año un $8,6 \%$, el segundo año un 9,7\% y el tercer año un 10,1\%de imposición de penas privativas de libertad.

Una posible razón de tal aumento es que una aplicación mecánica de la regla de exasperación penal contenida en el art. 351 del Código Procesal Penal pueda estar provocando un aumento de las condenas hacia el tramo más alto del art. 23 LRPA, generando sanciones únicas de internación en régimen cerrado por sobre los cinco años de duración. Algo similar puede estar ocurriendo con la valoración de la reincidencia al determinar la sanción de internación, incluso si ello no implica modificar el marco penal como en el caso anterior.

Aunque es objetivamente difícil definir qué porcentaje es aceptable en esta materia, más aún cuando las cifras se mantienen en una proporción relativamente baja, la tendencia al alza debe observarse con detenimiento. Como señalamos a propósito de las sanciones no privativas de libertad, un análisis más detallado que considere las posibilidades (y restricciones) jurídicas otorgadas por las reglas de determinación de la pena, además de los tiempos de duración de las condenas y las tasas de sustitución de las mismas, permitiría valorar de mejor forma este punto. En todo caso, un elemento objetivo que pudiera servir de parámetro para establecer, en el marco de un uso excepcional del encierro, el nivel de lo aceptable es la capacidad del Estado de encerrar adolescentes en condiciones dignas. ${ }^{56}$

\footnotetext{
${ }^{54}$ En el Reino Unido, en el reciente green paper del Ministry of Justice "Breaking the Cycle. Effective punishment, rehabilitation and sentencing of offenders", 2010, párrafo 245, p. 71, se identifica como un problema que el $57 \%$ de los jóvenes en prisión preventiva finalmente no sea condenado a una sanción privativa de libertad (custody), cifra que se pretende disminuir con estrategias alternativas a la prisión.

55 Cálculo efectuado como se indica en la nota $n^{\circ}$ 50. Así, si el 31 de diciembre de 2009 habían 565 adolescentes vigentes y el año 2010 fueron atendidos 1.723 , los ingresados entre enero y diciembre de 2010 se calculan restando a esta última cifra los vigentes del año anterior, obteniendo la cifra de 1.158 jóvenes.

${ }^{56}$ Sobre las deficientes condiciones de los centros privativos de libertad de adolescentes, consúltese Facultad de Derecho, Universidad Diego Portales, Informe Anual sobre Derechos Humanos en Chile 2008, pp. 107133, e Informe Anual sobre Derechos Humanos en Chile 2009, pp. 99-103, 105-107.
} 
BERRÍOS, Gonzalo. "La ley de responsabilidad penal del adolescente como sistema de justicia: análisis y propuestas".

\subsection{Cuarto objetivo: favorecer la conducta conforme a derecho, promover la integración social de los adolescentes y evitar la reincidencia delictiva}

Para analizar este objetivo preventivo-especial positivo sólo consideraremos una de sus dimensiones, la referida a la reincidencia o no del adolescente que fue objeto de una determinada sanción. Para ello revisaremos el estudio nacional sobre reincidencia de adolescentes infractores elaborado por la Fundación Paz Ciudadana, ${ }^{57}$ que se ejecutó sobre la base de los registros del Ministerio Público y del SENAME.

El estudio evalúa la reincidencia de la población condenada a las sanciones de internación en régimen cerrado, internación en régimen semicerrado, libertad asistida especial, libertad asistida y servicios en beneficio de la comunidad. Las tasas de reincidencia se miden desde el ingreso del condenado a cumplir con su sanción, salvo en el caso de la internación en régimen cerrado que se mide desde el egreso del centro privativo de libertad del SENAME.

En cuanto al concepto de reincidencia, el estudio la define de dos maneras: presentar una nueva causa y presentar una nueva condena. En cuanto al período de seguimiento empleado por la medición, se considera un mínimo de un año contado desde el ingreso o egreso de referencia, y en cuanto al número de casos, éste varía entre 4.800 y 4.793, según se mida nueva causa o nueva condena, respectivamente. ${ }^{58}$

El estudio no incluye a los sancionados a amonestación, multa y reparación del daño, esto es, a más del $20 \%$ del universo de condenas impuestas, ni tampoco a los adolescentes que fueron objeto de una salida alternativa o de la aplicación del principio de oportunidad. En el caso de los condenados a internación en régimen cerrado no fueron incluidos en la muestra del estudio quienes egresan desde las secciones juveniles dependientes de Gendarmería de Chile (en adelante, GENCHI), ${ }^{59}$ lo que provoca un sesgo en los resultados. ${ }^{60}$ Es por ello que sus resultados deben tomarse con cautela y sólo con respecto a las variables que se consideraron en el estudio.

\footnotetext{
${ }^{57}$ Fundación Paz Ciudadana, "Construcción de indicadores de reinserción social de adolescentes infractores de la ley penal", Informe final, 4 de mayo de 2010.

${ }^{58}$ Fundación Paz Ciudadana, "Construcción de indicadores”, cit. nota n 57, pp. 42 y 43.

${ }^{59}$ Los jóvenes que cumplen penas en internación en régimen cerrado se distribuyen en alrededor de un $74 \%$ en centros del SENAME y un 26\% en secciones juveniles de GENCHI, de acuerdo con información en poder del autor.

${ }^{60}$ Asumiendo que tales jóvenes debieran tener un peor pronóstico de no reincidencia, si se consideran las causales que permiten trasladarlos. El art. 56 LRPA permite el traslado a una sección juvenil si, además de haber cumplido los 18 años de edad, se ha evaluado la no conveniencia de que el joven permanezca en SENAME y, excepcionalmente, en caso de nueva condena o de infracciones graves al reglamento que afecten la vida e integridad física de otras personas.
} 
Polít. crim. Vol. 6, No 11 (Junio 2011), Art. 6, pp. 163-191.

[http://www.politicacriminal.cl/Vol_06/n_11/Vol6N11A6.pdf]

Tabla 7 Tasas de reincidencia por sanción

\begin{tabular}{|l|c|c|}
\hline \multicolumn{1}{|c|}{ Sanción } & $\begin{array}{c}\text { Tasa de reincidencia: } \\
\text { Cualquier nueva causa }\end{array}$ & $\begin{array}{c}\text { Tasa de reincidencia: } \\
\text { Nueva condena }\end{array}$ \\
\hline Internación en régimen cerrado & $79,6 \%$ & $65,9 \%$ \\
\hline Internación en régimen semicerrado & $83,2 \%$ & $66,8 \%$ \\
\hline Libertad asistida especial & $67,1 \%$ & $51,4 \%$ \\
\hline Libertad asistida & $63,2 \%$ & $48,4 \%$ \\
\hline Servicios en beneficios de la comunidad & $75,7 \%$ & $62,0 \%$ \\
\hline TOTAL & $70,1 \%$ & $55,2 \%$ \\
\hline
\end{tabular}

Fuente: elaboración propia a partir de los datos del Informe final "Construcción de indicadores de reinserción social de adolescentes infractores de la ley penal”, Fundación Paz Ciudadana, 2010, Tabla 17, p. 76.

De acuerdo con la Tabla 7, la tasa de reincidencia por nueva causa alcanza a un 70,1\% y la por nueva condena un 55,2\%. Las tasas de reincidencia de las sanciones privativas de libertad (régimen cerrado y semicerrado) son las más altas desde ambas perspectivas de medición.

Considerando el número de nuevas condenas que presenta el grupo de adolescentes reincidentes, los resultados arrojan que tras un año de seguimiento el 44,6\% registra sólo una nueva condena, el $24,7 \%$ dos condenas, el $13,4 \%$ tres, un $6,8 \%$ cuatro, el 4,4\% cinco y un $6,1 \%$ seis o más condenas. El 29,4\% de los reincidentes lo es por el mismo delito y el $50 \%$ de los casos se refieren a delitos contra la propiedad, tanto en la causa de referencia como en la causa de reincidencia. ${ }^{61}$

El estudio concluye que las tasas nacionales de reincidencia superan a las observadas en investigaciones internacionales, de las cuales el $70 \%$ muestra en promedio tasas de un $40 \%$ de reincidencia. ${ }^{62} 63$

Con respecto a las diferencias entre sanciones, se señala que "para saber el real impacto de una medida, se debe conocer la condición inicial de los jóvenes que ingresan y los perfiles de cada centro, ya que puede ser que justamente exista cierta acumulación de jóvenes con

\footnotetext{
${ }^{61}$ Fundación Paz Ciudadana, “Construcción de indicadores”, cit. nota $n^{\circ} 57$, pp. 82 y 83.

${ }^{62}$ Fundación Paz Ciudadana, "Construcción de indicadores", cit. nota ${ }^{\circ}$ 57, p. 101.

${ }^{63}$ Un estudio reciente en Inglaterra y Gales concluyó que la tasa general de reincidencia de la cohorte del 2009 fue de un $36,9 \%$, aunque la tasa por tipo de respuesta o sanción varía significativamente. Así, las community penalties tienen una tasa de reincidencia de un 66,9\%, las first-tier penalties de un 45,3\% y la custody de un $71,9 \%$. Significativamente más baja resulta la reincidencia de quienes recibieron una reprimenda o advertencia final (out-of-court disposal), pues la tasa alcanza sólo a un 23,7\%. Véase Ministry of Justice, "Reoffending of juveniles: results from the 2009 cohort, England and Wales", 17 March 2011, pp. 24 y 25.Por su parte, en Cataluña, España, en un estudio del 2005 se estableció que la tasa global de reincidencia de los menores de edad fue de un 22,7\%, alcanzando el internamiento un 62,8\%, la libertad vigilada un 31,9\%, la prestación de servicios en beneficio de la comunidad un $23,2 \%$, otras sanciones en medio abierto un $20 \%$ y los casos cuya respuesta fue una mediación-reparación un 12,7\% de reincidencia. CAPDEVILLA i CAPDEVILLA, Manel; FERRER PUIG, Marta; LUQUE REINA, M. Eulàlia, "La reincidència en el delicte en la justícia de menors", Justícia i Societat 26 (2006), Barcelona, pp. 104 y 107.
} 
BERRÍOS, Gonzalo. "La ley de responsabilidad penal del adolescente como sistema de justicia: análisis y propuestas".

un perfil de riesgo de reincidencia más alto en una medida u otra". ${ }^{64}$ Aun cuando ello pueda ser parte de la explicación, no se puede negar la responsabilidad estatal en alcanzar esta meta de la justicia juvenil. Así, la ejecución de las penas privativas de libertad-cuyas tasas son particularmente elevadas- en centros con una deficiente infraestructura y pobremente equipados para responder a las necesidades propias de los adolescentes, ${ }^{65}$ exacerba las dificultades inherentes al encierro producidas por la separación de la comunidad, la interrupción de la educación, la reducción de las perspectivas de empleabilidad futura y la confirmación de identidades delictivas. ${ }^{66}$ Las condiciones de vida de los privados de libertad, junto con violentar sus derechos fundamentales, impactan negativamente en las cifras de reincidencia posterior a la liberación.

Más allá de las conclusiones obtenidas por este estudio, lo cierto es que éste sólo representa un punto de partida, pues así como se carece de información previa a la reforma penal adolescente con que comparar sus resultados, sólo con posteriores mediciones de las tasas de reincidencia se podrá valorar la evolución que presenta la reincidencia en general y la de cada sanción en particular.

En todo caso, el propio concepto de reincidencia, así como las consecuencias que se derivan de su ocurrencia, deben ser profundamente revisados. La seriedad y frecuencia de los nuevos delitos no puede ser algo indiferente en su análisis. Si el desistimiento del delito no es un evento, sino un proceso de la persona que se extiende por un determinado período de tiempo y asociado al desarrollo de capital humano y social, ${ }^{67}$ es necesario contextualizar las nuevas infracciones en este proceso. En el desarrollo de futuras investigaciones debieran considerarse estos factores al evaluar el cumplimiento del objetivo de integración social y evitación de la reincidencia.

\section{Conclusiones y propuestas}

En este artículo identificamos los principales objetivos de la justicia juvenil con el fin de describir y valorar su nivel de cumplimiento por el sistema de justicia que las normas e instituciones de la Ley de Responsabilidad Penal del Adolescente han puesto en movimiento. Para ello hemos utilizado las estadísticas y estudios de diversas instituciones y especialistas, lo cual condicionó las posibilidades de análisis específicos del sistema, así como la profundidad que pudiera alcanzarse en algunos de esos casos. De ahí que las conclusiones que presentamos sean en algunos casos puntos de partida de nuevas preguntas y futuras investigaciones.

Entre los años 2008 y 2010 se verifica una disminución constante en el número de adolescentes imputados que ingresan al Ministerio Público y el peso proporcional de los

\footnotetext{
${ }^{64}$ Fundación Paz Ciudadana, "Construcción de indicadores", cit. nota n 57, p. 101.

${ }^{65}$ Facultad de Derecho, Universidad Diego Portales, “Informe Anual 2008” e "Informe Anual 2009”, cit. en nota $\mathrm{n}^{\circ} 56$.

${ }^{66}$ Nacro, "Effective practice with children and young people who offend-Part I", Youth crime briefing, September 2006, p. 2.

${ }^{67}$ McNEILL, Fergus, “ A desistance paradigm for offender management”, Criminology \& Criminal Justice 6 (1), 2006, pp. 45-55.
} 
Polít. crim. Vol. 6, Nº 11 (Junio 2011), Art. 6, pp. 163-191.

[http://www.politicacriminal.cl/Vol_06/n_11/Vol6N11A6.pdf]

adolescentes, en relación con los adultos, disminuye bajo el 10\% de acuerdo con los datos de la Defensoría. Sin embargo, esta reducción no ha significado una disminución de los adolescentes que son ingresados al sistema judicial, por el contrario, la tasa de judicialización de casos va en aumento. Por su parte, las detenciones de Carabineros confirman que la participación de los adolescentes es del orden del 10\% del total de infractores.

Los delitos cometidos por adolescentes se caracterizan por estar mayoritariamente relacionados con la propiedad y sólo quince delitos explican más del $84 \%$ de las infracciones cometidas por jóvenes. Desde el punto de vista de los hechos de mayor impacto público, destaca la tendencia a la baja de los robos con violencia, con intimidación y en lugares habitados. Por su parte, para comprender por qué aumentan las lesiones y las amenazas será necesario contar en el futuro con mejor información para aclarar cuán asociados se encuentran tales aumentos con las normas sobre violencia intrafamiliar, como ha ocurrido en adultos.

El estudio confirma que las mujeres adolescentes aumentan su participación a una velocidad mayor que los hombres adolescentes, información que debiera internalizarse prontamente por el sistema de justicia juvenil, pues implica nuevos desafíos: ofertas diferenciadas de programas y centros capaces de hacerse cargo efectivamente de sus necesidades específicas. Lo mismo puede señalarse respecto de los desafíos que enfrentarán los actores del sistema de justicia, como los jueces, fiscales y defensores.

Se constata que la justicia juvenil funciona en forma bastante similar a la justicia penal de adultos en cuanto a las políticas de desjudicialización y salidas alternativas, con porcentajes casi idénticos de aplicación de las suspensiones condicionales del procedimiento y los acuerdos reparatorios e, incluso, con porcentajes más altos en los adolescentes que en los adultos en la aplicación de sentencias condenatorias. Sólo el principio de oportunidad muestra una diferencia a favor del segmento de jóvenes. Sobre las formas de término de los casos al interior de la justicia penal para adolescentes, se aprecia un cambio negativo de la relación entre salidas alternativas y condenas, pues las salidas bajan un $10 \%$ en tres años, ubicándose en un $33,1 \%$, y las condenas aumentan ese mismo $10 \%$ en el período de análisis, sumando un $44 \%$ de los términos.

En nuestra opinión es fundamental corregir el comportamiento del sistema en el ámbito de la desjudicialización para potenciar su función dentro de la justicia juvenil. Una de las correcciones posibles es establecer una regulación autónoma de las salidas alternativas para adolescentes, que no tenga las limitaciones legales y los plazos que la ley ha establecido para los adultos. Ello permitiría aumentar el uso de estas formas de término, incluso en casos de jóvenes que hayan sido previamente condenados. En esa misma dirección debieran regularse formas de mediación penal y de prácticas restaurativas o de reparación para casos que actualmente terminan en sentencias condenatorias. El objetivo es aumentar las alternativas para así bajar las condenas y no agregarlas junto a éstas, fenómeno conocido como de "ampliación de la red". 
BERRÍOS, Gonzalo. "La ley de responsabilidad penal del adolescente como sistema de justicia: análisis y propuestas".

Con respecto a la aplicación de las sanciones se pudo constatar que nueve de cada diez penas no son privativas de libertad, en línea con los objetivos del sistema. Sin embargo, tal resultado se ve oscurecido por el hecho de que han aumentado las sanciones formales en desmedro de las salidas alternativas y porque no existe información que permita evaluar los datos según el tipo de delito y la alternatividad penal del caso concreto.

La mayor incidencia que han adquirido los servicios en beneficio de la comunidad, incluso por sobre las libertades asistidas, no se condice con la escasa regulación legal que existe respecto de su cumplimiento. Hoy queda al arbitrio y sin mayor control la definición del tipo de servicio a realizar, el lugar de ejecución, el período de tiempo en que deberán cumplirse las horas y las actividades adicionales preparatorias de la prestación del servicio comunitario. La exigencia de contar con el consentimiento del condenado difícilmente se cumple sin conocer los elementos concretos en que consistirá la sanción. Una solución posible es que el tribunal deba aprobar en un plazo razonable los tres primeros aspectos señalados, verificando que efectivamente exista acuerdo del adolescente sobre ellos (sistema de doble consentimiento). La ley puede a su vez determinar que las actividades preparatorias de la ejecución del servicio sean imputables a las horas de duración de la sanción.

En el caso de la privación de libertad los informes revisados por este estudio muestran un mayor paso de los adolescentes que de los adultos por audiencias judiciales de control de detención, lo que la transforma en la principal puerta de ingreso de los jóvenes al sistema, cifra especialmente alta en el caso de la región metropolitana. Junto con afectar las políticas de desjudicialización, ello también pudiera impactar en el alto número de condenas.

Sin embargo, los problemas más graves están centrados en la internación provisoria y en la pena de internación en régimen cerrado. Con respecto a la medida cautelar, si bien hay una disminución en su uso, hay un aumento importante en su duración, la que al tercer año alcanza a los 118 días promedio, casi 38 días adicionales respecto del primer año. Además, se vulnera sistemáticamente el principio de proporcionalidad con la sanción probable, entre un $65 \%$ y un $86 \%$, según se incluya o no al régimen semicerrado. Con respecto a la sanción, se constató un aumento progresivo en su aplicación, así como del conjunto de sanciones privativas de libertad, en este último caso desde un $8,6 \%$ a un $10,1 \%$ entre el primer y tercer año.

Para mitigar las situaciones descritas se podrían acortar como regla general los plazos de investigación en los casos en que el adolescente esté en internación provisoria, en especial si se sabe que la mayoría no serán condenados a una sanción privativa de libertad. En cuanto a la internación en régimen cerrado, una buena opción es la idea original del proyecto de ley de imponer siempre una sanción única en caso de pluralidad de delitos, garantizándose que ello no implicará automáticamente penas más graves ni privativas de libertad.

En cuanto a la reincidencia, si bien las tasas son relativamente altas, especialmente de las sanciones privativas de libertad, sólo comparando los resultados de futuros estudios con estos primeros datos se podrá valorar de mejor forma la eficacia del sistema. Sin embargo, 
Polít. crim. Vol. 6, No 11 (Junio 2011), Art. 6, pp. 163-191.

[http://www.politicacriminal.cl/Vol_06/n_11/Vol6N11A6.pdf]

es necesario contar con estudios más amplios que incluyan todas las formas de término de casos, así como la seriedad y frecuencia de las nuevas infracciones.

Finalmente, se desprende de la revisión de los distintos informes consultados que es fundamental la producción y difusión pública de mejores datos y, en especial, que éstos se encuentren desagregados en la mayor cantidad de variables posibles. Así se podrán efectuar análisis más precisos, que permitan comprender mejor los mecanismos por los cuales se produce la realidad reflejada parcialmente a través de las cifras. En esa dirección, es fundamental contar con estudios cualitativos complementarios a los cuantitativos para mejorar la comprensión y explicación del funcionamiento y nivel de logro alcanzado de los objetivos del sistema penal juvenil.

\section{BIBLIOGRAFÍA}

ALBRECHT, Peter Alexis, El derecho penal de menores, Trad. BUSTOS RAMÍREZ, Juan, Barcelona: PPU, 1990.

, "Respecto del futuro del derecho penal de menores -peligros y chances-", en: BUSTOS RAMÍREZ, Juan (Dir.), Un derecho penal del menor, Santiago: Ed. Jurídica Cono Sur, 1992.

BERNBURG, Jön Gunnar; KROHN, Marvin D., "Labeling, life chances, and adult crime: effects of official intervention in adolescence on crime in early adulthood", Criminology $\mathrm{N}^{\circ}$ 4, Vol. 41, 2003.

BERRÍOS, Gonzalo, "El nuevo sistema de justicia penal para adolescentes", Revista de Estudios de la Justicia $\mathrm{N}^{\circ} 6$ (2005).

BERRÍOS, Gonzalo; VIAL, Luis, "3 años de vigencia Ley de responsabilidad penal del adolescente. 8 de junio de 2007 a 7 de junio de 2010", Defensoría Penal PúblicaUNICEF, 2011.

BLANCO, Javiera, "Violencia y delincuencia juvenil: desafíos en relación con los programas y respuestas del sistema", Serie Conceptos $\mathrm{N}^{\circ} 18$, Fundación Paz Ciudadana, 2010.

BUSTOS RAMÍREZ, Juan, "Hacia la desmitificación de la facultad reformadora en el derecho penal de menores: por un derecho penal del menor", en: BUSTOS RAMÍREZ, Juan (Dir.), Un derecho penal del menor, Santiago: Ed. Jurídica Cono Sur, 1992.

Derecho penal del niño-adolescente, Santiago: EJS, 2007.

CAPDEVILLA i CAPDEVILLA, Manel; FERRER PUIG, Marta; LUQUE REINA, M. Eulàlia, "La reincidència en el delicte en la justícia de menors", Justícia i Societat 26, Barcelona, 2006.

CILLERO, Miguel, “Adolescentes y sistema penal. Proposiciones desde la Convención sobre los Derechos del Niño", Revista Justicia y Derechos del Niño N² (2000).

, "La responsabilidad penal de adolescentes y el interés superior del niño", Revista Justicia y Derechos del Niño $\mathrm{N}^{\circ} 7$ (2005).

, "Ley $\mathrm{N}^{\circ} 20.084$ sobre Responsabilidad Penal de Adolescentes", Anuario de Derechos Humanos 2006. 
BERRÍOS, Gonzalo. "La ley de responsabilidad penal del adolescente como sistema de justicia: análisis y propuestas".

CILLERO, Miguel; BERNALES, Martín, "Derechos humanos de la infancia/adolescencia en la justicia 'penal de menores' de Chile: evaluación y perspectivas”, Revista de Derechos del Niño $\mathrm{N}^{\circ} 1$ (2002).

Corte Interamericana de Derechos Humanos, caso "Instituto de Reeducación del Menor 'Panchito López' v. Paraguay", sentencia de 2 de septiembre de 2004.

COUSO, Jaime, "Principio educativo y (re) socialización en el derecho penal juvenil", Revista Justicia y Derechos del Niño Nº 8 (2006).

"La política criminal para adolescentes y la Ley 20.084", en: VV. AA.

Estudios de derecho penal juvenil I, Santiago: Centro de Documentación, Defensoría Penal Pública, 2009.

CRUZ MÁRQUEZ, Beatriz, Educación y prevención general en el derecho penal de menores, Madrid: Marcial Pons, 2006.

Defensoría Penal Pública, "Primer año de vigencia Ley de responsabilidad penal adolescente (8 de junio de 2007 a 7 de junio de 2008)", 2009. "Informe estadístico anual 2010".

DE FERARI, Luis Ignacio, "Quince años de espera...hacia la creación de un sistema de reemplazo: notas sobre la génesis y desarrollo de la ley sobre responsabilidad penal de adolescentes", Revista Justicia y Derechos del Niño N 8 (2006).

DUCE, Mauricio, "El derecho a un juzgamiento especializado de los jóvenes infractores en el derecho internacional de los derechos humanos y su impacto en el diseño del proceso penal juvenil", Revista Ius et Praxis N 1, Año 15, 2009.

, "El derecho a un juzgamiento especializado de los jóvenes infractores en el nuevo proceso penal juvenil chileno", Política Criminal Vol. 5, N 10 (2010), p. 336, http://www.politicacriminal.cl/Vol_05/n_10/Vol5N10A1.pdf

DÜNKEL, Frieder; VAN ZYL SMIT, Dirk, "Implementación del encarcelamiento juvenil y derecho constitucional en Alemania", en: SERRANO MAÍlLO, Alfonso; GUZMÁn DÁlBORA, José Luis (Eds.), Procesos de infracción de normas y de reacción a la infracción de normas: dos tradiciones criminológicas. Nuevos estudios en homenaje al profesor Alfonso Serrano Gómez, Madrid: Dykinson, 2008.

Facultad de Derecho, Universidad Diego Portales, Informe Anual sobre Derechos Humanos en Chile 2008.

Humanos en Chile 2009.

Informe Anual sobre Derechos

Fundación Paz Ciudadana, "Construcción de indicadores de reinserción social de adolescentes infractores de la ley penal", Informe final, 4 de mayo de 2010.

HAZARD JR., Geoffrey, "Criminal justice system: overview", Encyclopedia of Crime and Justice, Vol. 2, New York: The Free Press, 1988, pp. 450 y ss., citado en DUCE, Mauricio; RIEGO, Cristián, Proceso penal, Santiago: Ed. Jurídica de Chile, 2007.

HERNÁNDEZ BASUALTO, Héctor, "El nuevo derecho penal de adolescentes y la necesaria revisión de su "teoría del delito"”, en: VV. AA., Estudios de derecho penal juvenil I, Santiago: Centro de Documentación, Defensoría Penal Pública, 2009.

MARTÍNEZ, Jorge (coord.), "Informe de diagnóstico de la implementación de la Ley 20.084, junio 2007-marzo 2010", Servicio Nacional de Menores, 2010.

McARA, Lesley y McVIE, Susan, "Youth crime and justice: key messages from the Edinburgh Study of Youth Transitions and Crime", Criminology \& Criminal Justice 10 (2), 2010. 
Polít. crim. Vol. 6, No 11 (Junio 2011), Art. 6, pp. 163-191.

[http://www.politicacriminal.cl/Vol_06/n_11/Vol6N11A6.pdf]

McNEILL, Fergus, “A desistance paradigm for offender management”, Criminology \& Criminal Justice 6 (1), 2006.

Mensaje de S.E. el Presidente de la República con el que inicia un proyecto de ley que establece un sistema de responsabilidad de los adolescentes por infracciones a la ley penal (boletín N 3021-07), Boletín de Sesiones de la Cámara de Diputados, Sesión $24^{\mathrm{a}}$, de 6 de agosto de 2002, Legislatura $347^{\mathrm{a}}$ Ordinaria.

Ministerio Público, "Boletín estadístico" años 2008, 2009 y 2010.

"Instrucción general que imparte criterios de actuación en materia de responsabilidad penal adolescente, Ley 20.084”, Oficio FN N 483/2009.

Ministry of Justice, "Breaking the Cycle. Effective punishment, rehabilitation and sentencing of offenders", Green paper, 2010.

,"Re-offending of juveniles: results from the 2009 cohort, England and Wales", 17 March 2011.

Nacro, "Effective practice with children and young people who offend-Part I", Youth crime briefing, September 2006.

NOGUEIRA ALCALÁ, Humberto, Derechos fundamentales y garantías constitucionales, t. 1, $2^{\text {a }}$ edición corregida, Santiago: Ed. Librotecnia, 2008.

PETROSINO, Anthony; TURPIN-PETROSINO, Carolyn; GUCKENBURG, Sarah, "Formal System Processing of Juveniles: Effects on Delinquency", Campbell Systematic Reviews 2010:1, DOI: 10.4073/csr.2010.1.

RUTTER, Michael; GILLER, Henri; HAGELL, Ann, La conducta antisocial de los jóvenes, Madrid: Cambridge University Press, 2000.

SAMPSON, Robert J.; LAUB, John H., "A life-course theory of cumulative disadvantage and the stability of delinquency", en: THORNBERRY, Terence (Ed.), Developmental Theories of Crime and Delinquency, Advances in Criminological Theory Vol. 7, New Brunswick: Transaction Publishers, 1997.

Servicio Nacional de Menores, "Boletín Estadístico Anual”, años 2008, 2009 y 2010.

VALENZUELA, Jonathan, "La pena y la educación. Una aproximación al fundamento de la pena juvenil", Revista de Estudios de la Justicia $\mathrm{N}^{\circ} 11$ (2009).

VÁZQUEZ GONZÁLEZ, Carlos, Delincuencia juvenil. Consideraciones penales y criminológicas, Madrid: Ed. Colex, 2003. 